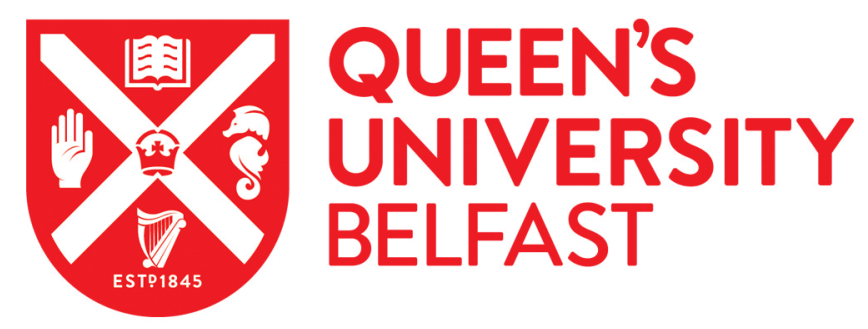

\title{
Return Spillovers Between White Precious Metal ETFs: The Role of Oil, Gold, and Global Equity
}

Lau, M. C. K., Vigne, S. A., Wang, S., \& Yarovaya, L. (2017). Return Spillovers Between White Precious Metal ETFs: The Role of Oil, Gold, and Global Equity. International Review of Financial Analysis.

https://doi.org/10.1016/j.irfa.2017.04.001

Published in:

International Review of Financial Analysis

Document Version:

Peer reviewed version

Queen's University Belfast - Research Portal:

Link to publication record in Queen's University Belfast Research Portal

Publisher rights

24 month embargo

Copyright 2017 Elsevier.

This manuscript is distributed under a Creative Commons Attribution-NonCommercial-NoDerivs License

(https://creativecommons.org/licenses/by-nc-nd/4.0/), which permits distribution and reproduction for non-commercial purposes, provided the author and source are cited.

\section{General rights}

Copyright for the publications made accessible via the Queen's University Belfast Research Portal is retained by the author(s) and / or other copyright owners and it is a condition of accessing these publications that users recognise and abide by the legal requirements associated with these rights.

Take down policy

The Research Portal is Queen's institutional repository that provides access to Queen's research output. Every effort has been made to ensure that content in the Research Portal does not infringe any person's rights, or applicable UK laws. If you discover content in the Research Portal that you believe breaches copyright or violates any law, please contact openaccess@qub.ac.uk. 


\title{
Return Spillovers Between White Precious Metal ETFs: The Role of Oil, Gold, and Global Equity
}

\author{
Marco Chi Keung Lau ${ }^{\mathrm{a}}$, Samuel A. Vigne ${ }^{\mathrm{b}}$, Shixuan Wang ${ }^{1 \mathrm{c}}$, Larisa \\ Yarovaya $^{\mathrm{d}}$ \\ ${ }^{a}$ Newcastle Business School (NBS), Northumbria University, Newcastle University, \\ Newcastle upon Tyne, NEI 8ST, United Kingdom \\ email: chi.lau@northumbria.ac.uk (corresponding author) \\ ${ }^{b}$ Queen's Management School, Queen's University Belfast, BT9 5EE, Northern Ireland, \\ United Kingdom \\ email: s.vigne@qub.ac.uk \\ ${ }^{c}$ Department of Economics, University of Birmingam, B15 2TT, United Kingdom \\ email: shixuan_wang@hotmail.com \\ ${ }^{d}$ Lord Ashcroft Business School, Anglia Ruskin University, CM1 1SQ, United Kingdom \\ email: drlarisayarovaya@gmail.com
}

\begin{abstract}
This paper investigates the relationship between white precious metals and gold, oil and global equity by means of spillovers and volatility transmission. Relying on the recently introduced ETFs, this study is the first to analyse return spillovers derived from an E-GARCH model and to take into account frequency dynamics to understand changes in connectedness across periods of time. Results uncover numerous channels of return transmission across the selected ETF markets over the last 10 years and highlight the role of gold ETFs as the most influential market in the sample. Furthermore, our work provides insights into the characteristics of white precious metal markets using a hidden semi-Markov model. Finally, we argue that even though silver and platinum have gained more importance as investment assets over the last few years, palladium still very much remains an industrial metal.
\end{abstract}

Keywords: Precious Metals, Oil, Spillovers, Volatility Transmission

JEL Code F30; F65; G12

\footnotetext{
${ }^{1}$ The research of Shixuan Wang was supported by the Economic and Social Research Council (UK) [grant number ES/JS50001X/1] and a Royal Economics society Junior Fellowship
} 


\section{Introduction}

Silver, platinum and palladium have traditionally been viewed as precious metals used for production purposes rather than as investment vehicles. Recently however, white precious metals have received increased attention from investors due to the introduction of new Exchange Traded Funds (ETFs). Figures 1 to 4 show the increasing importance of investment demand for the four major precious metals over time.

\section{Insert Figures 1 to 4 about here}

Being relatively new asset classes (data for palladium and platinum ETFs is only available from the $1^{\text {st }}$ of August 2010 onward), the problem of interconnectedness between white metal markets is still somehow unexplored in academic literature. This paper fills a gap by investigating the dynamic linkages between silver, platinum and palladium ETFs, as well as other significant asset classes, such as gold, oil and global equities.

More precisely, we test how gold, oil and global equity markets affect the behaviour of white metal markets. There are many reasons to believe that linkages between these target markets should exist. Gold and silver are somewhat close substitutes because of their use in jewellery production, their role as a monetary reserve and their active use in industrial production. Therefore, a high correlation and information transmission between these two markets can be expected. However, an empirical answer to the matter has still not been delivered by fellow researchers. Lucey and Tully (2006) and Sari et al. (2010) for example show that the long-run impact of gold returns on silver is quite important, where the latter example shows that gold explains $16 \%$ of the variation of silver returns, $10 \%$ of the variation of platinum returns and $7 \%$ of the variation of palladium returns. Furthermore, this relationship is also observed the other way around: white metal returns transmit information to each other and to gold. On the other hand, Balcilar et al. (2015) find that by taking different regimes into account, the effect of 
the gold price on silver can be as high as 17 times greater than the effect of the silver price on gold.

The relationship between oil and gold is well-evidenced in literature. Baffes (2007) argues that a rise in the price of oil by $1 \$$ results in an increase of $0.34 \$$ in the price of gold and an increase of $0.50 \$$ in the price of silver. O'Connor et al. (2015) summarise the relevant literature by arguing that oil drives inflation and inflation drives gold.

The importance of global equity price movements for the price of gold has been demonstrated by Baur and Lucey (2010) and Baur and McDermott (2010), both proving that gold has safe haven qualities during market turmoils. The hedging potential of white precious metals against equity prices has also been studied over the past few years. Hillier et al. (2006) consider the time period between 1976 and 2004 and find that silver has a hedging potential during high volatility periods, but that this ability is more pronounced for gold and platinum. Differentiating between bullish and bearish environments, Belousova and Dorfleitner (2012) argue that adding silver to a portfolio during bullish periods reduces volatility and enhances returns, while during bear markets, platinum is shown to lose its diversification properties.

Our study augments the existing literature in several ways. First, this paper examines the time-frequency dynamics of connectedness for gold, silver, platinum, palladium, oil and global equity ETFs using the new variance decomposition methodology proposed by Barunik and Krehlik (2015). Therefore, we discuss new stylized facts about cyclical properties of transmission mechanism in the precious metals markets and examine the time-frame of connectedness. Second, we provide valuable insights to white precious metal investors by running an E-GARCH model in order to quantify the impacts of daily returns of oil, gold and equity on the return of silver, platinum and palladium. Finally, we use the Hidden semi-Markov model (HSMM) to provide novel evidence on the return characteristics of white metal ETF 
markets.

The remainder of this paper is organised as follows: section 2 discusses the relevant academic literature, sections 3 and 4 shed light on data and the methodology while sections 5 and 6 present and discuss the results. A conclusion of the paper is provided in section 7 .

\section{Literature Review}

White precious metals gained increased attraction as investment vehicles over the past few years. Recent findings point towards the impossibility to consider precious metals as a single asset class due to the distinct differences between them (Batten et al. (2010)) with gold having unique characteristics. It is not surprising that the relationship between gold and white precious metals has been the subject of research over the past few years. Early on, Chan and Mountain (1988) and Ma and Soenen (1988) argue for the existence of a long-run relationship between gold and silver. A break in the relationship between the two metals is found to have occurred during the 1990's (Ciner (2001)) even though a positive long-run relationship persisted over time (Lucey and Tully (2006)). Regarding gold's relationship with platinum, Kearney and Lombra (2009) find the relationship to be negative, even though an empirical result can not be drawn as the relationship between gold and platinum was time-varying between 1985 and 2006 - the timewindow considered in the study. Chng and Foster (2012) rely on a VAR framework consisting of all four precious metals and find evidence for a significant effect of the convenience yields of gold and silver on platinum and palladium returns. Considering the similarity of the four precious metals, which are all important for industry but also considered financial investment vehicles, a relationship between them should exist and including gold in this study is therefore vitally important when trying to understand pricing patterns of white precious metals.

Oil is probably the most important resource used in industry and there- 
fore considered to be a signal of future industrial production activity. If industrial activity increases, the demand for oil would rise and with it the oil price. In the light of precious metals as production input, an increase in industrial production will lead to an increased demand for precious metals and will therefore have a positive effect on their price. Considering precious metals as investment vehicles, O'Connor et al. (2015) argue that oil drives inflation which in turn drives the price of gold. In the light of white precious metals as investment substitutes of gold, the same effect should be observable for silver, platinum and palladium. Conciliating both arguments, a rising oil price positively influences the investment and industrial demand of precious metals. Indeed, Adrangi et al. (2003) find evidence for a positive relationship between silver and both the US Consumer Price Index and the American Industrial Production Index. Recently however, Bampinas and Panagiotidis (2015) argues that the positive relationship between silver and US inflation is a modern phenomenon since a long-run positive relationship can't be observed between 1791 and 2010. Results somewhat conflicting with Taylor (1998), who finds that silver was a hedge against inflation between 1914 and 1996. Working with recent data from 1976 to 2004, Hillier et al. (2006) find evidence for silver's and platinum's positive relationship with inflation. Following the argumentation that money supply is the very root of inflation (Artigas (2010)), Batten et al. (2010) provide evidence for the importance that monetary variables have on palladium. Focusing on the direct link between oil and white precious metals, and not via the detour of inflation, Soytas et al. (2009) focus their research on the Turkish economy and find evidence for a positive relationship between oil price shocks and the price of silver, pointing towards the industrial importance of silver in the Turkish economy. Jain and Ghosh (2013) observe similar results for the Indian economy and augment the research by looking at platinum. A noteworthy argumentation of the authors is that price increases of precious metals occur because of price increases in oil, again channeled through inflation. It 
seems however, that the relationship between oil and silver seems to disappear on a more global level (Bhar and Hammoudeh (2011)), though Bildirici and Türkmen (2015) take into account a larger time window of observations and indeed finds evidence for a long-run cointegration between global silver and oil prices: indicating that the relationship might be time-varying. In a recent study that takes into account daily prices of silver, platinum and palladium between July 1993 and January 2014, Behmiri and Manera (2015) conclude that negative oil price shocks do not affect the volatility of silver, while positive oil price shocks decrease the volatility of silver prices. Results are slightly different for platinum, where negative oil price shocks increase volatility while positive oil price shocks have a cooling effect on the volatility of platinum prices. Regarding palladium, any oil price shock, whether positive or negative, increases the volatility of palladium prices, pointing towards the industrial importance of the metal.

The relationship between precious metals and equity prices has to be understood in the light of the possible hedging and safe haven potential of the metals, akin to their properties as investment assets. Hillier et al. (2006) indeed prove that gold, silver and platinum offer diversifying benefits when added to a portfolio of US and international stocks, results supported by Conover et al. (2009). Belousova and Dorfleitner (2012) differentiate between bull and bear markets and strengthen the attractiveness of silver as an investment asset because it reduces portfolio volatility and enhances returns during bull markets, while reducing portfolio risk during bear markets. Platinum and palladium lower portfolio volatility in bull markets but these diversification benefits seem to vanish away in bear markets. The benefits of platinum and palladium are questionable when added to European portfolios. Sarafrazi et al. (2014) indeed argue that gold and silver seem to be the only precious metals that offer diversification benefits against a variety of European stock and bond portfolios. Recently, Lucey and Li (2015) took the discussion a step further and looked at the safe haven implications of 
white precious metals against the S\&P 500 and US 10 year bonds. Results show that platinum and palladium acted as safe havens against falling US equity prices more often than silver did.

Volatility spillovers between precious metals was studied by Batten et al. (2010) and linked to fluctuations in debt, equity, monetary and financial variables. Results indicate an important effect of financial variables on platinum and palladium but not on silver. It seems that silver is a case apart, where the price volatility is a function of the volatility of the other precious metals. Empirically however, between 1986 and 2006, the volatility of the four precious metals were influenced by each others volatility, highlighting the interdependence of the different metals. Batten et al. (2015) go a step further into the investigation of return spillovers amongst precious metals and find that while gold and silver show consistency in the spillovers between each other, platinum and palladium are separated from the two, even separated from themselves. Results in favour of silver's close relationship to gold due to it's attractiveness as a financial investment. Morales and Andreosso-O'Callaghan (2011) look at the time window between 1995 and 2007 to understand the effects of the Asian crisis and the Global Financial crisis on volatility spillovers amongst precious metals. In line with Batten et al. (2010) clear evidence for volatility persistence between the four precious metals is observed, but it seems that gold, not silver, is the case apart since other metals do not influence the price of gold. Adding oil into their analysis, Antonakakis and Kizys (2015) model a Forecast Error Variance Decomposition (FEVD) framework consisting of the four precious metals, oil and exchange rates and find that gold, silver and platinum are net transmitters of returns and volatility spillovers, while palladium and oil are net receivers - results in contrast with Batten et al. (2015) where silver is a net receiver of volatility spillovers. Balcilar et al. (2015) propose to differentiate between high and low volatility regimes and conclude that gold is the most informative commodity in high volatility regimes while gold, platinum and 
palladium are the most informative commodities in low volatility regimes results questioning the importance of silver in a spillover model.

\section{Data and Preliminary Data Analysis}

This paper employs daily ETF prices of gold, silver, platinum palladium, oil and global equity ${ }^{2}$, between the $19^{\text {th }}$ of June 2006 and the $18^{\text {th }}$ of June 2016. However, the earliest data available for platinum and palladium is from the $1^{\text {st }}$ of August 2010. Daily returns are defined as:

$$
R(t)=\ln \left(P_{t}\right)-\ln \left(P_{t-1}\right)
$$

where $\ln \left(P_{t}\right)$ is the natural logarithm of the closing price at date $t$ and $\ln \left(P_{t-1}\right)$ is the natural logarithm of the closing price at date $t-1$. The conditional distribution that produces a sequence of observations with length $d$ can be specified as:

$$
\mathbb{P}_{i, d}\left(\boldsymbol{X}_{t+1: t+d}\right)=\mathbb{P}\left(\boldsymbol{X}_{t+1: t+d} \mid \boldsymbol{S}_{t+1: t+d}=i\right)
$$

where $i$ represents one of the states (i.e. $i \in\{1,2, \ldots, m\}), \boldsymbol{X}_{t+1: t+d}$ denotes the sequence of observations from time $t+1$ to $t+d$, and $\boldsymbol{S}_{t+1: t+d}$ indicates the sequence of states starting at time $t+1$ and ending at $t+d$. Therefore, state $i$ beginning at $t+1$ produces a sequence of $d$ observations. Details on the distribution of return series are discussed in section 4.4.

There are 2,518 ETF observations of silver, gold, oil and global equity, and 1,623 observations for platinum and palladium ETFs. Summary statistics of price returns in the six ETF markets can be found in Table 1, where sample means, medians, maximums, minimums, standard deviations, skewness, kurtosis, and the Jarque-Bera (JB) statistic are reported. The JB

\footnotetext{
${ }^{2}$ The data was downloaded from www.etfdb.com. The following six ETFS are included in our analysis: iShares Silver Trust (SLV), ETFS Physical Platinum (PPLT), ETFS Physical Palladium (PALL), SPDR Gold Trust (GLD), United States Oil Fund (USO), Vanguard Total Stock Market ETF (VTI).
} 
Statistics indicate a departure from normality and the existence of nonlinear components in the data generating process.

\section{Insert Table 1 about here}

Table 2 reports the unit root test results, where various tests reject the null hypothesis of a unit root at the 0.01 significance level. It can therefore be concluded that the price return series are stationary.

\section{Insert Table 2 about here}

\section{Methodology}

\subsection{Regime-switch cointegration test}

The regime-switch cointegration technique of Gregory and Hansen (1996) are conducted to test for market integration as the sample may contain timevarying elements and structural breaks. Hatemi-J (2008) further develops a model that incorporates the impact of two structural breaks on both the intercept and the slope (i.e. two regime shifts). The model used in this study could be specified in the bivariate case as:

$$
y_{1 t}=\mu_{1}+\mu_{2} D_{1 t}+\mu_{3} D_{2 t}+\lambda_{1}^{T} y_{2 t}+\lambda_{2}^{T} y_{2 t} D_{1 t}+\lambda_{3}^{T} y_{2 t} D_{2 t}+\varepsilon_{t}
$$

where $D_{1 t}$ and $D_{2 t}$ are dummy variables defined as:

$$
D_{1 t}=\left\{\begin{array}{l}
0, \text { if } t \leq\left[n \tau_{1}\right] \\
1, \text { if } t>\left[n \tau_{1}\right]
\end{array}\right.
$$

and

$$
D_{2 t}=\left\{\begin{array}{l}
0, \text { if } t \leq\left[n \tau_{2}\right] \\
1, \text { if } t>\left[n \tau_{2}\right]
\end{array}\right.
$$

The date of pairwise breaks is estimated with the unknown parameters $\tau_{1} \in(0,1)$ and $\tau_{2} \in(0,1)$. The null hypothesis of no cointegration between markets is tested by the $Z_{t}$ statistic of Phillips (1987). The $Z_{t}$ statistic is estimated as $Z_{t}^{*}=i n f_{\left(\tau_{1} \tau_{2}\right) \in T} Z_{t\left(\left(\tau_{1} \tau_{2}\right)\right.}$, where $T=(o .15 n, 0.85 n)$. 


\section{2. $E-G A R C H$}

An E-GARCH model is used to estimate the impacts of daily returns of gold, oil and equity on the return of white precious metals. The specification of the conditional variance equation ensures that the conditional variance is strictly positive, and therefore releases the non-negative constraints of a simple GARCH model. On the other hand, the conditional variance specification allows asymmetric innovations of bad news in a way that it generates higher volatility than good news. The mean equation can be modelled as:

$$
R_{t}=\delta_{0}+\sum_{i}^{p} \lambda_{i} R_{t-i}+\delta_{1} G L D_{t}+\delta_{2} U S O_{t}+\delta_{3} V T I_{t}+v_{t}
$$

where $R_{t}$ is the daily return of white precious metal ETFs, the notations $G L D, U S O$ and VTI represent gold, oil and global equity respectively. The variance equation in equation 7 is specified such that an E-GARCH $(1,1)$ specification can be written as:

$$
\ln \left(h_{t}\right)=\omega+\sum_{i=1}^{p} \alpha_{i}\left|\frac{v_{t-1}}{h_{t-i}^{2}}\right|+\sum_{k=1}^{r} \gamma_{k} \frac{v_{t-k}}{h_{t-k}^{2}}+\sum_{j=1}^{q} \beta h_{t-j}
$$

where $\omega$ is the intercept, $h_{t}$ denotes the conditional volatility, $v_{t-1}$ represents the innovation term in period $t-i$, and $\gamma_{k}$ captures asymmetric captures asymmetric positive and negative shocks. The presence of the asymmetric leverage effect is indicated with the term $\gamma_{k} \neq 0$.

\subsection{Frequency Dynamics of Connectedness}

We employ the methodology suggested by Barunik and Krehlik (2015) to measure the dynamics and intensity of ETF return spillovers across the above mentioned asset classes, taking frequency dynamics into account. Diebold and Yilmaz (2012) adopt the generalised variance decomposition methodology of Pesaran and Shin (1998) to obtain directional connectedness. Barunik and Krehlik (2015) in turn apply spectral representations of variance decomposition locally to retrieve time-frequency (Stiassny (1996)). 
This frequency domain analysis enables us to analyse long-run, medium-run, or short-run connectedness using frequency dependent connectedness measures. While Diebold and Yilmaz (2012) employ a VAR model, Barunik and Krehlik (2015) adopt the spectral method of Stiassny (1996) and Dew-becker and Giglio (2016) to measure unconditional connectedness relations in frequency domain. The following frequency response function can be used to decompose the generalised impulse response function - consider the spectral behaviour of series $X_{t}$ as:

$$
S_{x}(\omega)=\sum_{h=0}^{\infty} E\left(X_{t} X_{t-h}\right) e^{-i h \omega}=\Psi\left(e^{-i h \omega}\right) \sum \Psi\left(e^{i h \omega}\right)
$$

where $\omega$ is the frequency, $\infty$ implies infinite horizon relations in the setting and $\Psi\left(e^{-i h \omega}\right)=\sum_{h=0}^{\infty} \Psi_{h} e^{-i h \omega}$ (Barunik and Krehlik (2015)). The unconditional generalised forecast error variance decomposition (GFEVD) on a particular frequency $\omega$ is specified as:

$$
(\Theta(\omega))_{i, j}=\frac{\sigma_{j j}^{-1} \sum_{h=0}^{\infty}\left(\Psi\left(e^{-i h \omega}\right) \sum\right)_{i, j}^{2}}{\sum_{h=0}^{\infty}\left(\Psi\left(e^{-i h \omega}\right) \sum \Psi\left(e^{i h \omega}\right)\right)_{i, i}}
$$

where 9 can be standardised as:

$$
(\tilde{\Theta}(\omega))_{i, j}=\frac{(\Theta(\omega))_{i, j}}{\sum_{j=1}^{k}(\Theta(\omega))_{i, j}}
$$

The accumulative connectedness table (i.e. specified over an informative frequency band) proposed by Barunik and Krehlik (2015) over an arbitrary frequency band $d=(a ; b)$ can be expressed as:

$$
\left(\tilde{\Theta}_{d}\right)_{i, j}=\int_{a}^{b}(\tilde{\Theta}(\omega))_{i, j} d \omega
$$

Therefore the overall connectedness within the frequency band $d$ can be defined as:

$$
C^{d}=\frac{\sum_{i=1, i \neq j}^{k}\left(\tilde{\Theta}_{d}\right)_{i, j}}{\sum_{i, j}\left(\tilde{\Theta}_{d}\right)_{i, j}}=1-\frac{\sum_{i=1}^{k}\left(\tilde{\Theta}_{d}\right)_{i, i}}{\sum_{i, j}\left(\tilde{\Theta}_{d}\right)_{i, j}}
$$

It is important to note that $C^{d}$ close to unity implies strong connections within the spectral band $(d=(a ; b))$ while the aggregate connectedness 
amongst the variables could be low. We are interested in measuring the contribution of one market $(i \neq j)$ to another market $i$, which can be defined as within from connectedness on the spectral band $d$ :

$$
C_{i \leftarrow .}^{d}=\sum_{j=1, i \neq j}^{k}\left(\tilde{\Theta}_{d}\right)_{i, j}
$$

In the same way, we can measure the variance from market $i$ to another market as the within to connectedness on the spectral band $d$ :

$$
C_{i \rightarrow \cdot}^{d}=\sum_{j=1, i \neq j}^{k}\left(\tilde{\Theta}_{d}\right)_{j, i}
$$

Another measure is used to quantify the difference between variance received and variance given from an asset. This within net connectedness is defined as:

$$
C_{i, n e t}^{d}=C_{i \rightarrow \cdot}^{d}-C_{i \leftarrow}^{d}
$$

If $C_{i, n e t}^{d}$ is positive, it indicates that the variable $i$ transmits more information than it receives from the other variables in a stable VAR system. The pairwise connectedness between market $i$ and $j$ can be specified as:

$$
C_{i, j}^{d}=\left(\tilde{\Theta}_{d}\right)_{j, i}-\left(\tilde{\Theta}_{d}\right)_{i, j}
$$

The contribution of a particular frequency band $d$ to the aggregate measure has to be weighted. Barunik and Krehlik (2015) show that the aggregate measure on the frequency band $d$ is specified as:

$$
\tilde{C}^{d}=C^{d} \cdot \Gamma(d)
$$

Where the spectral weight $\Gamma(d)=\frac{\sum_{i, j=1}^{k}\left(\tilde{\Theta}_{d}\right)_{i, j}}{\sum_{i, j}(\Theta)_{i, j}}=\frac{\sum_{i, j=1}^{k}\left(\tilde{\Theta}_{d}\right)_{i, j}}{k}$ is the contribution of frequency band $d$ to the whole VAR system and $C^{d}$ is the total connectedness measure on the connectedness tables $\left(\tilde{\Theta}_{d}\right)$ corresponding to an arbitrary frequency of band $d$. The total connectedness measures $C$ can be obtained by $S^{g}(H)=\sum_{d} \tilde{C}^{d}$ (Diebold and Yilmaz (2012)). 
The time-frequency dynamics of connectedness for ETF markets can be obtained by using the spectral representations of variance with a moving window of 250 trading days. A lag length of two is used to capture the dynamics in the window; the results for time-frequency decomposition of return connectedness is shown in Table 7 . The frequency bounds for daily data should be interpreted in cycles, with a classical spectrum between 0 and $\frac{\pi}{2}$. Since we work with daily data, the highest possible frequency is 0.5 cycles per day, which amounts to 2 days. We investigate the dynamics for 1 to 5 days, 5 to 20 days, 20 to 60 days, and 60 to 250 days (in other words weekly, monthly, quarterly and yearly cycles). The $H$ steps forecast horizon is set to be 100 which is a common approximation in literature.

\subsection{Hidden Semi-Markov Model}

A hidden semi-Markov model (HSMM) is used to analyse return characteristics of the white precious metal ETF market. Figure 5 shows the structure of the HSMM. The model can be decomposed into two processes: the unobservable state process $\left(\boldsymbol{S}_{1: T}=s_{1}, s_{2}, \ldots, s_{T}\right)$ and the observation

process $\left(\boldsymbol{X}_{1: T}=x_{1}, x_{2}, \ldots x_{T}\right)$. The sojourn time of each process follows a sojourn time distribution which can be defined as:

$$
d_{i}(u)=\mathbb{P}\left(s_{t+u+1} \neq j, s_{t+1: t+u}=j \mid s_{t+1}=j, s_{t} \neq j\right)
$$

The state transition probability of the data generating process can be defined as:

$$
\begin{array}{r}
\gamma_{(i, d)\left(j, d^{\prime}\right)}=\mathbb{P}\left(\boldsymbol{S}_{t+1: t+d^{\prime}}=j \mid \boldsymbol{S}_{t-d-1: t}=i\right) \\
\text { where } i \neq j, \quad i, j \in\{1,2, \ldots, m\}
\end{array}
$$

Specifically, the system stays in state $i$ for $d$ periods from $t-d+1$ to $t$ and then transits to state $j$ for $d^{\prime}$ periods from $t+1$ to $t+d^{\prime}$. Note that $\gamma_{(i, d)\left(i, d^{\prime}\right)}=0$ since the sojourn time is controlled by the sojourn time distribution in the HSMM. The transition probability matrix (TPM) for the 
HSMM can be specified as:

$$
\Gamma=\left(\begin{array}{cccc}
0 & \gamma_{\left(1, d_{1}\right)\left(2, d_{2}\right)} & \cdots & \gamma_{\left(1, d_{1}\right)\left(m, d_{m}\right)} \\
\gamma_{\left(2, d_{2}\right)\left(1, d_{1}\right)} & 0 & \cdots & \gamma_{\left(2, d_{2}\right)\left(m, d_{1 m}\right)} \\
\vdots & \vdots & \ddots & \vdots \\
\gamma_{\left(m, d_{m}\right)\left(1, d_{1}\right)} & \gamma_{\left(m, d_{m}\right)\left(2, d_{2}\right)} & \cdots & 0
\end{array}\right)
$$

We follow Bulla and Bulla (2006) and apply the right-censored type HSMM because the assumption is more realistic for our ETF data. We set the conditional distribution as normal distribution and sojourn time distribution as negative binomial distribution in this study as it fits our data well. We use the expectation-maximisation algorithm to estimate the model and the Viterbi algorithm to globally decode the sequence of states.

\section{Insert Figure 5 about here}

\section{Empirical Results}

\subsection{Cointegration}

Table 3 reports the relationship between the three white precious metals (i.e. silver, platinum and palladium) and other asset classes (i.e. gold, oil and global equity). The results show that all markets are well integrated while break dates can be identified around the years 2011, 2012, 2013, and 2014 .

\section{Insert Table 3 about here}

The results on the relationship between gold and silver prices are mixed in the literature. Ciner (2001) does not observe a long-run relationship between gold and silver prices and concludes that the two markets are rather segmented. This conclusion however is based only on the conventional cointegration test of Johansen (1991) and is inconsistent with other studies (see for example Wahab et al. (1994), Escribano and Granger (1998) or Adrangi 
and Chatrath (2002)). This inconsistency is raised because of the fact that the standard cointegration tests for the null hypothesis of no-cointegration can have substantially reduced power and hence lead to erroneous conclusions (see Gregory and Hansen (1996) for more details). Overall, our approach confirmed the presence of cointegration between all nine commodity pairs: silver-gold, silver-oil, silver-equity, platinum-gold, platinumoil, platinum-equity, palladium-gold, palladium-oil, and finally, palladiumequity.

\subsection{E-GARCH Spillover effects}

Tables 4 to 6 present the parameters of the univariate $\operatorname{E-GARCH}(1,1)$ model for each white metal ETF market. Panel A of each table shows the estimated coefficients, standard errors, z-statistics and p-values for the conditional mean equation as in equation 6 . All three white precious metals exhibit a significant own mean spillover from their first lagged returns. In all cases, the mean spillovers are positive, results in line with the literature on other financial assets in the field. Table 4 presents the empirical results of return spillover from other asset classes to silver ETFs: there is a positive and significant relationship between the mean return in the silver market and the return in the gold market. In particular, a $1 \%$ increase of daily returns in the gold market leads to an increase of $1.2813 \%$ of daily silver returns. The response of the silver price to a $1 \%$ increase in oil ETFs is $0.2685 \%$ and $0.0788 \%$ to global equity. The response of silver to a $1 \%$ oil price increase is therefore much lower than the results obtained by other studies. Baffes (2007) finds that a $1 \$$ increase of the oil price leads to a $0.50 \$$ increase of the silver price, while Bildirici and Türkmen (2015) finds evidence for a $1.33 \%$ increase of the price of silver in response to a $1 \%$ increase of the price of oil. Results pointing towards the shift of silver from an industrial to an investment asset.

Insert Table 4 about here 
Table 5 presents the empirical results for platinum ETFs: we find evidence for a positive and significant relationship between the mean return in the platinum market and returns in the gold market. More specifically, a $1 \%$ increase of daily returns in the gold market leads to a $0.73 \%$ increase of daily returns in the silver market. The response of platinum to a $1 \%$ increase in oil ETFs is $0.2538 \%$, and $0.0723 \%$ to global equity.

\section{Insert Table 5 about here}

Table 6 presents the results for palladium, again, a positive and significant relationship between the mean return in the platinum and the gold market is observed. The effect of the gold market on palladium ETFs is that a $1 \%$ change in gold market returns lead to an increase of $0.6525 \%$ in the price of palladium ETFs. The response of palladium ETFs to a $1 \%$ increase in the price of oil is $0.555 \%$ and $0.16078 \%$ for global equity. Furthermore, we can detect the presence of an asymmetric leverage effect indicated by the term $\gamma_{k} \neq 0$.

\section{Insert Table 6 about here}

\subsection{Frequency Dynamics of Connectedness}

Table 7 displays the decomposition of time-frequency dynamics of connections. The largest portion of connections is created from the higher frequency of one week up to one month (top panel of Table 7), with a value of $43.181 \%$. The connectedness of monthly, quarterly, and yearly cycles is $7.963 \%, 2.29 \%$, and $0.573 \%$ respectively. Considering the time dynamics of frequency connections, an interesting observation is that higher frequency bands dominate lower frequency bands. In particular, connectedness has been driven mostly by information up to one week. The result is consistent with the recent study of Barunik et al. (2013) in which the authors argue for the empirical importance of frequency sources of connectedness as shocks to volatility may have different implications on uncertainty. An example 
being mining costs, where uncertainty may reveal fundamental changes in investor's future price expectation, while the influence of this long-run or fundamental impact may be different to short-run source of uncertainty.

Table 7 also displays the net-spillover indices for individual ETF markets. The weekly contribution of the silver market to other markets is $71.634 \%$, furthermore, silver contributes $30.559 \%$ of the spillover index to gold as a close substitute. In contrast, oil only transmits $12.725 \%$ to other ETF markets. Gold receives 56.294\%, the most spillovers from other markets, making it the largest net-recipient of price spillovers. To summarise, silver, palladium and equity are net-contributors to the spillover index, while gold, oil and platinum are net-recipients.

\section{Insert Table 7 about here}

Figures 6 to 14 illustrate the time-frequency dynamics of connectedness for silver, platinum, palladium and other markets. The decomposition of the bi-directional connectedness of frequency bands between 1 and 5 days are denoted by the red line, between 5 and 20 days are denoted by the black line, between 20 and 60 days are denoted by the blue line, and between 60 and 120 days are denoted by the green line. Several interesting observations can be made. The gold-silver market maintains the highest spillover index as expected, but the connectedness is decreasing since August 2013. The smallest connectedness is between gold and palladium. Regarding equity, the equitysilver market exhibits the highest spillover index, while the connectedness is recently decreasing since March 2014; the smallest connectedness is found for platinum. Regarding oil, the oil-palladium market is found to have the highest spillover-index, underlining the industrial importance of the metal.

Insert Figures 6 to 14 about here 


\subsection{Hidden Semi-Markov Model Results}

Table 8 displays the estimated parameters of the fitted two-state HSMM for silver, platinum, and palladium ${ }^{3}$. Considering daily returns of all three white metals ETFs, the variances of state 2 are much higher than those of state 1 . Hence, state 2 corresponds to the higher volatility state, while state 1 corresponds to the low volatility state. Although the mean of state 2 for all three ETFs are negative, z-statistics indicate that the negative means of state 2 are not significantly different from zero. Therefore, there is no statistical evidence to associate high volatility with low mean of returns. Additionally, z-statistics show that the means of state 1 for silver and platinum are not significantly different from zero, while palladium on the other hand has a significantly positive mean for its low volatility state.

The average sojourn time of either state 1 or state 2 for palladium is much longer than for silver and platinum, suggesting that the volatility clustering effect in palladium is more persistent. The average sojourn time for silver is shortest among the three ETFs. Its low volatility state (avg. 17 days) lasts longer than its high volatility state (avg. 10 days). This indicates that the states of silver can frequently transits between low and high volatility states, which can be confirmed from the decoding results later on.

\section{Insert Table 8 about here}

Table 9 displays the estimated parameters of the fitted three-state HSMM. State 1, state 2 and state 3 are linked to low, medium and high volatility respectively. Regarding palladium, the Transition Probability Matrix (TPM) indicates that state 2 always occurs after state 1 . The probability of state 2 to transit to state 1 is $23.25 \%$ and to state 3 is $76.75 \%$. Furthermore, state 2 always occurs after state 3 and can be considered a "buffer zone" between the other two states. A "buffer zone" is also observed for the TPM of silver,

\footnotetext{
${ }^{3}$ The TPM for two-state HSMM is not reported because it is always a 2 by 2 matrix with diagonal entries of value 1 and offdiagonal entries of value 0 .
} 
but not for platinum. This may result from the fact that platinum does not have enough days of high volatility (only 26 days) during our sample period.

Palladium has a relatively long sojourn time for its low volatility state (avg. 169 days). In contrast, silver has a comparatively long sojourn time for its high volatility state (avg. 147 days). For platinum, its low and medium volatility states both have long sojourn times, with an average of 145 and 116 days respectively. Hence, the sojourn time of different level volatility states are quite different for the three metals.

\section{Insert Table 9 about here}

\subsection{Decoding Results}

Figures 15 to 17 show the global decoding results of fitted two-state HSMMs for the three ETFs. The green backgrounds stand for the low volatility state (i.e. State 1) while the red background represents the high volatility state (i.e. State 2). We can observe that palladium and platinum share a large overlap of the periods of low and high volatility states. There are four remarkable periods:

1. Before 2013, palladium was in its high volatility state. Platinum went into a high volatility state from low volatility until the middle of 2011, with some short periods of high volatility states in 2010 and early of 2011. The high volatility of silver before 2013 mainly occurred between the end of 2011 and the middle of 2012.

2. In the middle of 2013, all three ETFs were in the high volatility state.

3. During 2014, all three ETFs were in the low volatility state.

4. After June 2015, both palladium and platinum went into a high volatility state, while silver remained in the low volatility state.

\section{Insert Figures 15 to 17 about here}

Figures 18 to 20 show the global decoding results of fitted three-state HSMMs for the three ETFs. The purple background stands for the low 
volatility state, the green background stands for the medium volatility state, and finally, the red background stands for the high volatility state. Palladium has two relatively long periods of high volatility, one before 2012 and the other around the beginning of 2016. Platinum does not have a long period of high volatility in our sample period. Its high volatility state lasted only for a few days. Platinum and palladium were both mainly in low volatility states from 2013 to the middle of 2015 . We can still observe that palladium and platinum share a large overlap of the same level of volatility states. However, silver shows a different pattern since it has three long periods of high volatility states, which are in 2011, the middle of 2013, and the beginning of 2015. Additionally, its low and medium volatility states last for very short periods and transit to each other frequently.

\section{Insert Figures 18 to 20 about here}

\section{Discussion of Results}

Our findings indicate that gold plays an important role for silver ETFs, followed by platinum and palladium ETFs. Due to their low cost, low investment scale and their ability to track the gold price very closely (Ivanov (2013)), gold ETFs are a popular investment asset since their introduction in 2003. The strong relationship between gold and silver is supported by previous literature. Ma and Soenen (1988) find a strong relationship in both the spot and the futures markets and propose an arbitrage strategy based on that relationship. Subject to a short time window of 6 years during the 1990's, Ciner (2001) argues for the nonexistence of a long-run relationship between the two metals. Lucey and Tully (2006) support the existence of a break in the relationship during the 1990's but find that on the long-run, the relationship between gold and silver is positive. Batten et al. (2013) question a profit making strategy based on the gold-silver relationship as the two series don't immediately revert towards their long-term mean. Kearney and Lombra (2009) prove that the relationship between gold and platinum 
evolved over time and ran through both positive and negative episodes, while Chng and Foster (2012) argue that the effect of the convenience yield of gold on platinum is significant. Batten et al. (2010) finds that the volatility of silver, platinum and palladium is influenced by gold, results in line with Batten et al. (2015) who find evidence for time-variation in the relationship: spillovers from gold to palladium weakened over time and vanished around 2010 and 2012. Our results indicate a persistent and strong relationship between gold and the other three precious metals and indicate that gold is a net-recipient of price spillovers; findings consistent with previous results by pointing towards a positive and significant relationship between gold and white precious metal returns.

O'Connor et al. (2015) argue that oil drives inflation, which in turn drives the price of gold. An applied example of that framework can be found in Narayan et al. (2010), where the authors argue that a $1 \$$ oil price increase results in an average increase of the price of gold by $0.356 \$$. This argumentation could be an explanation for the observed positive relationship between oil and all three white precious metals. In light of this relationship, a similar argumentation can be used for silver. Taylor (1998) and Adrangi et al. (2003) find evidence for silvers ability to function as a hedge against inflation; results rejected by Bampinas and Panagiotidis (2015) who considers 200 years of data and concludes that silver is not a long-run hedge against US inflation and only a hedge against UK inflation in a time-varying framework. Previous research somewhat support our findings: Bhar and Hammoudeh (2011) rely on different model specifications and show that no significant relationship between silver and oil can be observed, results in contrast to Jain and Ghosh (2013) who found evidence for Granger causality between oil and silver, but not between oil and platinum. Even though Charlot and Marimoutou (2014) find evidence for correlation between oil and silver/platinum, the correlation coefficient is quite small. In a recent paper and one of the few considering the effects of oil on palladium, Behmiri 
and Manera (2015) find that positive oil price shocks decrease the volatility of the silver price while oil price shocks have an inverse relationship with platinum price volatility. Observations are different for palladium, where a positive oil price shock increases the volatility of palladium, underlining the industrial importance of the metal. Reboredo and Uddin (2016) continue the investigation between oil and precious metal prices and find evidence for a systematic impact of downward oil price movements on downward metal price movements. On the other hand, upwards oil price movements spill over on all precious metal prices except palladium. We add to the ongoing investigation on the relationship between oil and white precious metals by showing that the impact of oil on white precious metals is unimportant.

In academic literature, gold is considered an effective a hedging tool against equity prices. Sumner et al. (2010) consider volatility spillovers between January 1970 and April 2009 and find that no spillovers occurred from gold to US stocks, highlighting the hedging potential of gold. More formally, Baur and Lucey (2010) and Baur and McDermott (2010) show that indeed, a long-run relationship between gold and equity prices can be observed on the long-run. Sarafrazi et al. (2014) take the three studied white precious metals into account and find that silver has diversification benefits for European stock and bond portfolios. Morales and Andreosso-O'Callaghan (2014) take an international approach and indicate an insignificant relationship between silver and the Dow Jones and a significant relationship between silver and both the FTSE100 and the Nikkei225. Platinum on the other hand is found to have a significant positive relationship with the Dow Jones and the Nikkei225, but the relationship with the FTSE100 is insignificant. The formal methodology proposed by Baur and Lucey (2010) is used in Lucey and $\mathrm{Li}$ (2015) and applied to silver, platinum and palladium. In line with Sarafrazi et al. (2014), Lucey and Li (2015) find that on average, silver is a weaker equity hedge that gold, and that platinum and palladium have a much weaker relationship with equity prices than gold and silver. An empir- 
ical answer to the nature of the relationship between white precious metals and equity prices still needs to be derived. Our results are however in line with previous findings: a relationship with equity prices was observed by means of the cointegration analysis even though the importance of equity ETFs on white metal ETFs is fairly weak.

\section{Conclusion}

This paper provided new empirical evidence on return spillovers between white precious metal markets from 2006 to 2016. The results improve the understanding of the impact that gold, oil and global equity has on the dynamics of the connectedness of white precious metal ETFs. This study highlighted the shift of silver and platinum from an industrial towards an investment asset, making the results not only important from a theoretical perspective, but also highly significant for a broad range of investors and practitioners. The findings can be summarised as follows.

First, the application of a regime-switch cointegration test taking into account structural breaks revealed that all market pairs (silver-gold, silveroil, silver-equity, platinum-gold, platinum-oil, platinum-equity, palladiumgold, palladium-oil, and palladium-equity) are cointegrated.

Second, E-GARCH model results display a positive and significant relationship between the mean of returns in the gold markets and the mean of returns on silver, platinum and palladium markets - confirming the role of gold as a main source of return spillovers on white metal ETF markets. These findings are in line with previous evidence documented by Kearney and Lombra (2009), Chng and Foster (2012), Batten et al. (2010), and Batten et al. (2015) to name but a few. The results reveal that gold has a higher influence on white precious metals than oil or equity has. Indeed, we show that oil and equity have only a small effect on white precious metal prices.

Third, this paper reported new evidence on dynamic time-frequency connectedness across precious metals, oil and equity, using the approach sug- 
gested by Barunik et al. (2013). The results show that higher frequency bands dominate lower frequency bands; more specifically, connectedness has been driven mostly by information up to one week. The values of netspillover indices for individual ETF markets indicate that silver, palladium and equity are net-contributors of spillovers, while gold, oil and platinum are net-recipients. As expected, the gold-silver market pair maintains the highest spillover index, but the connectedness is decreasing since August 2013. Furthermore, the oil-palladium market is found to have the highest spillover-index, underlining the industrial importance of the metal.

Finally, estimation results of a two-state HSMM identified that the presence of volatility clustering effect in palladium is more pronounced than for both silver and platinum. Decoding the results highlighted four periods during which the high and lower volatility states of white precious metal market experienced significant changes. A three-state HSMM found that palladium has a relatively long sojourn time during its low volatility state, while silver has a comparatively long sojourn time during its high volatility state - evidence pointing towards the speculative aspects of silver. Platinum is found to have long sojourn times during both the low and medium volatility states. These findings provide useful insights into the nature of volatility of silver, platinum and palladium, and are useful for the creation of successful investment strategies or to hedge the risks of specific portfolios. 


\section{References}

Adrangi, B. and A. Chatrath (2002). The Dynamics of Palladium and Platinum Prices. Computational Economics 19, 179-195.

Adrangi, B., A. Chatrath, and K. Raffiee (2003). Economic Activity, Inflation, and Hedging: The Case of Gold and Silver Investments. The Journal of Wealth Management 6(2), 60-77.

Antonakakis, N. and R. Kizys (2015). Dynamic spillovers between commodity and currency markets. International Review of Financial Analysis 41, 303-319.

Artigas, J. C. (2010). Linking global money supply to gold and to future inflation. World Gold Council.

Baffes, J. (2007). Oil Spills on Other Commodities. Resources Policy 32(3), $126-134$

Balcilar, M., S. M. Hammoudeh, and N.-A. F. Asaba (2015). A regimedependent assessment of the information transmission dynamics between oil prices, precious metal prices and exchange rates. International Review of Economics \& Finance 40, 72-89.

Bampinas, G. and T. Panagiotidis (2015). Are gold and silver a hedge against inflation? A two century perspective. International Review of Financial Analysis 41, 267-276.

Barunik, J., E. Kocenda, and L. Vacha (2013). Asymmetric connectedness of stocks: How does bad and good volatility spill over the U.S. stock market? Available on SSRN, 1-28.

Barunik, J. and T. Krehlik (2015). Measuring the frequency dynamics of financial and macroeconomic connectedness. Available on SSRN, 1-33. 
Batten, J. A., C. Ciner, and B. M. Lucey (2010). The macroeconomic determinants of volatility in precious metals markets. Resources Policy 35(2), $65-71$.

Batten, J. A., C. Ciner, and B. M. Lucey (2015). Which precious metals spill over on which, when and why? Some evidence. Applied Economics Letters 22(6), 466-473.

Batten, J. A., C. Ciner, B. M. Lucey, and P. G. Szilagyi (2013). The structure of gold and silver spread returns. Quantitative Finance 13(4), 561570 .

Baur, D. G. and B. M. Lucey (2010, may). Is Gold a Hedge or a Safe Haven? An Analysis of Stocks, Bonds and Gold. The Financial Review 45(2), $217-229$.

Baur, D. G. and T. K. McDermott (2010, aug). Is gold a safe haven? International evidence. Journal of Banking 65 Finance 34(8), 1886-1898.

Behmiri, N. B. and M. Manera (2015). The role of outliers and oil price shocks on volatility of metal prices. Resources Policy 46(2), 139-150.

Belousova, J. and G. Dorfleitner (2012). On the diversification benefits of commodities from the perspective of euro investors. Journal of Banking E Finance 36(9), 2455-2472.

Bhar, R. and S. M. Hammoudeh (2011). Commodities and financial variables: Analyzing relationships in a changing regime environment. International Review of Economics and Finance 20(4), 469-484.

Bildirici, M. E. and C. Türkmen (2015). Nonlinear causality between oil and precious metals. Resources Policy 46(2), 202-211.

Bulla, J. and I. Bulla (2006). Stylized facts of financial time series and hidden semi-Markov models. Computational Statistics 83 Data Analysis 51(4), 2192-2209. 
Chan, M. W. L. and D. C. Mountain (1988). The Interactive and Causal Relationships Involving Precious Metal Price Movements: An Analysis of the Gold and Silver Markets. Journal of Business 83 Economic Statistics 6(1), 69-77.

Charlot, P. and V. Marimoutou (2014). On the relationship between the prices of oil and the precious metals: Revisiting with a multivariate regime-switching decision tree. Energy Economics 44, 456-467.

Chng, M. T. and G. M. Foster (2012). The Implied Convenience Yield of Precious Metals: Safe Haven versus Industrial Usage. Review of Futures Markets 20(4), 349-94.

Ciner, C. (2001). On the long run relationship between gold and silver prices: A note. Global Finance Journal 12(2), 299-303.

Conover, C. M., G. R. Jensen, R. R. Johnson, and J. M. Mercer (2009). Can Precious Metals Make Your Portfolio Shine? The Journal of Investing 18(1), 75-86.

Dew-becker, I. and S. Giglio (2016). Asset Pricing in the Frequency Domain: Theory and Empirics. Review of Financial Studies.

Diebold, F. X. and K. Yilmaz (2012). Better to give than to receive: Predictive directional measurement of volatility spillovers. International Journal of Forecasting 28(1), 57-66.

Escribano, A. and C. W. Granger (1998). Investigating the relationship between gold and silver prices. Journal of Forecasting 17(2), 81-107.

Gregory, A. W. and B. E. Hansen (1996). Residual-based tests for cointegration with regime shifts in models. Journal of Econometrics 70, 99-126.

Hatemi-J, A. (2008). Tests for cointegration with two unknown regime shifts with an application to financial market integration. Empirical Economics 35(3), 497-505. 
Hillier, D., P. Draper, and R. W. Faff (2006). Do Precious Metals Shine? An Investment Perspective. Financial Analysts Journal 62(2), 98-106.

Ivanov, S. I. (2013). The influence of ETFs on the price discovery of gold, silver and oil. Journal of Economics and Finance 37(3), 453-462.

Jain, A. and S. Ghosh (2013). Dynamics of global oil prices, exchange rate and precious metal prices in India. Resources Policy 38(1), 88-93.

Johansen, S. (1991). Estimation and Hypothesis Testing of Cointegration Vectors in Gaussian Vector Autoregressive Models. Econometrica 59(6), $1551-1580$.

Kearney, A. A. and R. E. Lombra (2009). Gold and platinum: Toward solving the price puzzle. Quarterly Review of Economics and Finance 49(3), 884-892.

Lucey, B. M. and S. Li (2015). What precious metals act as safe havens, and when? Some US evidence. Applied Economics Letters 22(1), 35-45.

Lucey, B. M. and E. Tully (2006). The evolving relationship between gold and silver 1978-2002: evidence from a dynamic cointegration analysis: a note. Applied Financial Economics Letters 2(1), 47-53.

Ma, C. K. and L. A. Soenen (1988). Arbitrage Opportunities in Metal Futures Markets. The Journal of Futures Markets 8(2), 199-209.

Morales, L. and B. Andreosso-O'Callaghan (2011). Comparative analysis on the effects of the Asian and global financial crises on precious metal markets. Research in International Business and Finance 25 (2), 203-227.

Morales, L. and B. Andreosso-O'Callaghan (2014). Volatility analysis of precious metals returns and oil returns: An ICSS approach. Journal of Economics and Finance 38(3), 492-517. 
Narayan, P. K., S. Narayan, and X. Zheng (2010). Gold and oil futures markets: Are markets efficient? Applied Energy 87(10), 3299-3303.

Newey, W. K. and K. D. West (1994). Automatic Lag Selection in Covariance Matrix Estimation. The Review of Economic Studies 61(4), 631-653.

O'Connor, F. A., B. M. Lucey, J. A. Batten, and D. G. Baur (2015). The financial economics of gold A survey. International Review of Financial Analysis 41, 186-205.

Perron, P. (1989). The Great Crash, the Oil Price Shock, and the Unit Root Hypothesis. Econometrica 57(6), 1361-1401.

Pesaran, M. H. and Y. Shin (1998). Generalized impulse response analysis in linear multivariate models. Economics Letters 58(1), 17-29.

Phillips, P. C. (1987). Time Series Regression With a Unit Root. Econometrica 55(2), 277-301.

Reboredo, J. C. and G. S. Uddin (2016). Do financial stress and policy uncertainty have an impact on the energy and metals markets? A quantile regression approach. International Review of Economics and Finance 43, $284-298$.

Sarafrazi, S., S. M. Hammoudeh, and P. Araújo Santos (2014). Downside risk, portfolio diversification and the financial crisis in the euro-zone. Journal of International Financial Markets, Institutions and Money 32(1), $368-396$.

Sari, R., S. M. Hammoudeh, and U. Soytas (2010, mar). Dynamics of oil price, precious metal prices, and exchange rate. Energy Economics 32(2), $351-362$.

Soytas, U., R. Sari, S. M. Hammoudeh, and E. Hacihasanoglu (2009). World oil prices, precious metal prices and macroeconomy in Turkey. Energy Policy 37(12), 5557-5566. 
Stiassny, A. (1996). A spectral Decomposition for Structural VAR Models. Empirical Economics 21, 535-555.

Sumner, S. W., R. R. Johnson, and L. A. Soenen (2010). Spillover effects among gold, stocks, and bonds. Journal of CENTRUM Cathedra 3(2), $106-120$.

Taylor, N. J. (1998). Precious metals and inflation. Applied Financial Economics 8(2), 201-210.

Vogelsang, T. (1993). Essays on testing for nonstationarities and structural change in time series models. Ph. D. thesis.

Wahab, M., R. A. Cohn, and M. K. Lashgari (1994). The Gold-Silver Spread: Integration, Cointegration, Predictability, and Ex-Ante Arbitrage. The Journal of Futures Markets 14(6), 709-756. 
Figure 1: Demand for Gold in Tonnes (Source: GFMS Surveys)

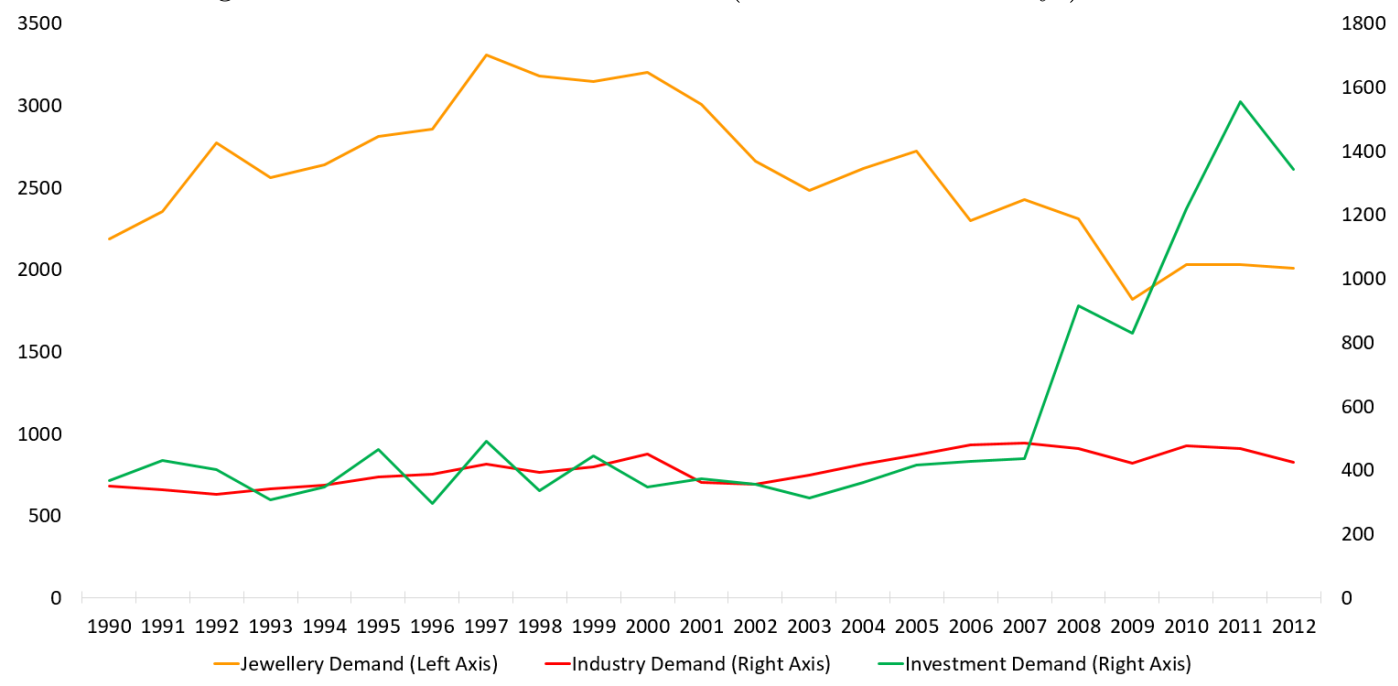

Figure 2: Demand for Silver in Million Ounces (Source: GFMS Surveys)

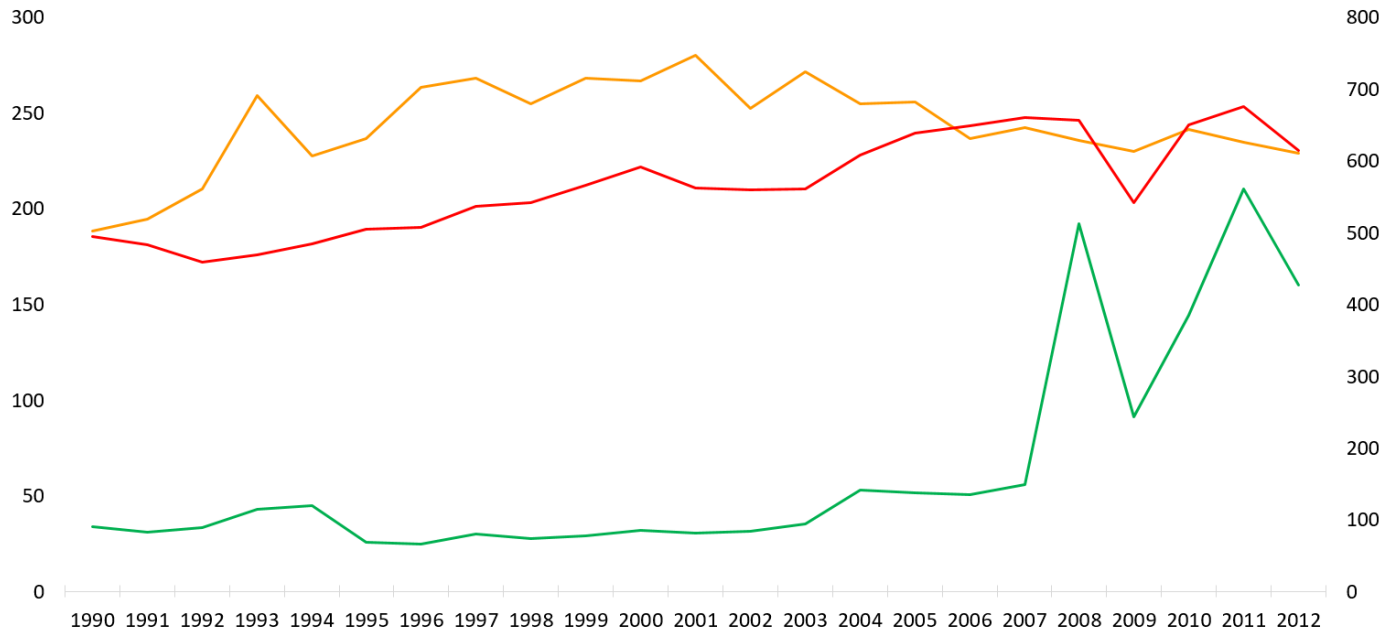

19901991199219931994199519961997199819992000200120022003200420052006200720082009201020112012

—Jewellery and Silverware Demand (Left Axis) _ _ Investment Demand (Left Axis) —Industry Demand (Right Axis) 
Figure 3: Demand for Platinum in Thousand Ounces (Source: Johnson Matthey)

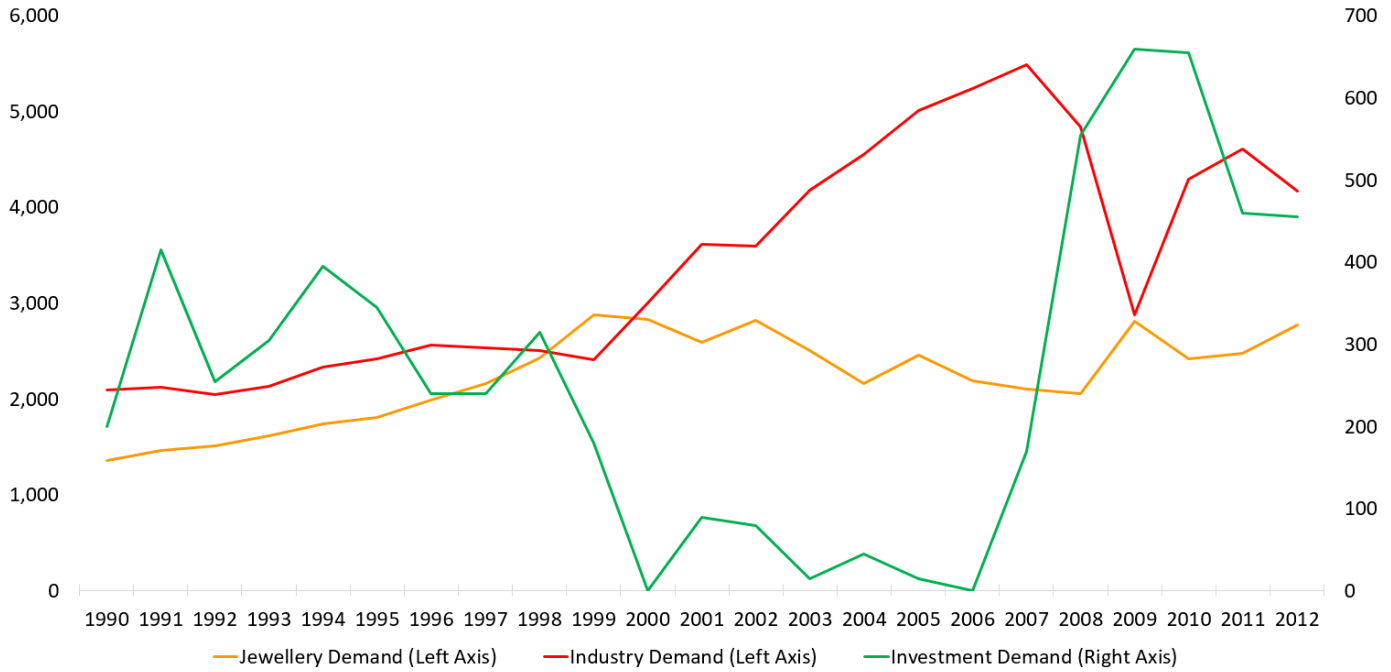

Figure 4: Demand for Palladium in Thousand Ounces (Source: Johnson Matthey)

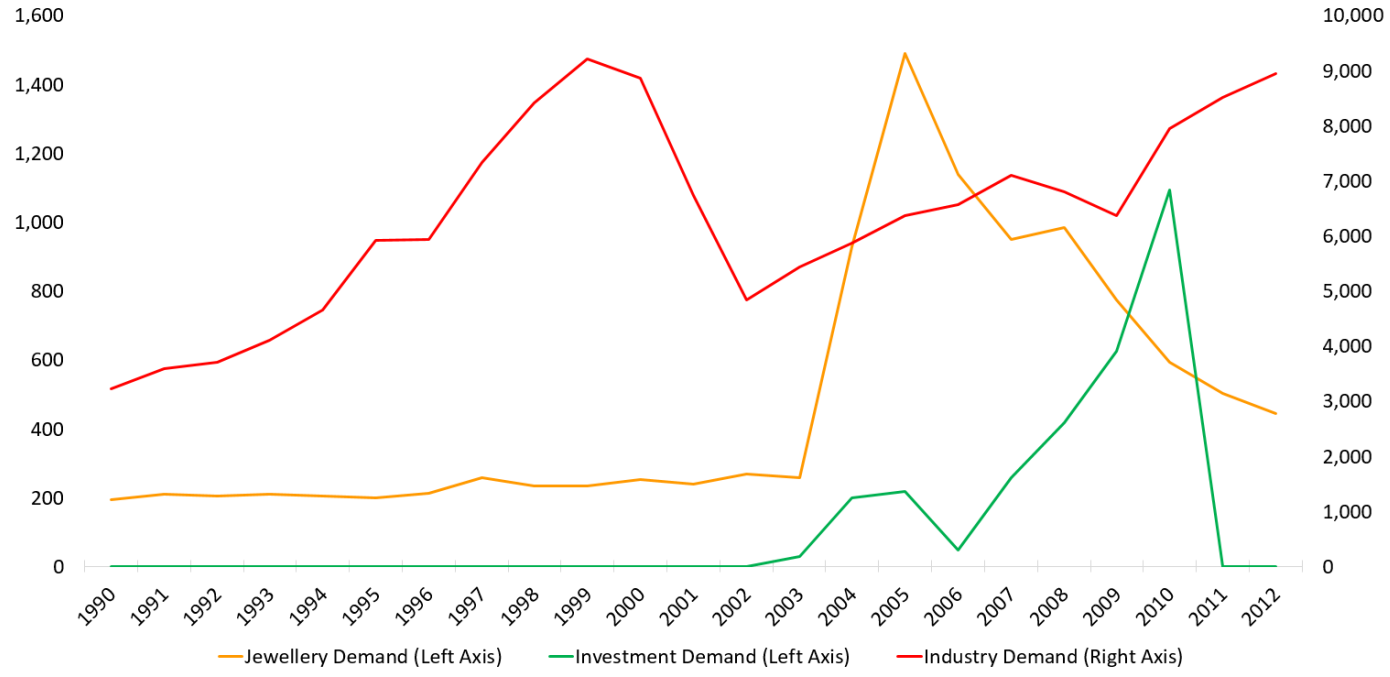


Figure 5: Directed Graph of HSMM

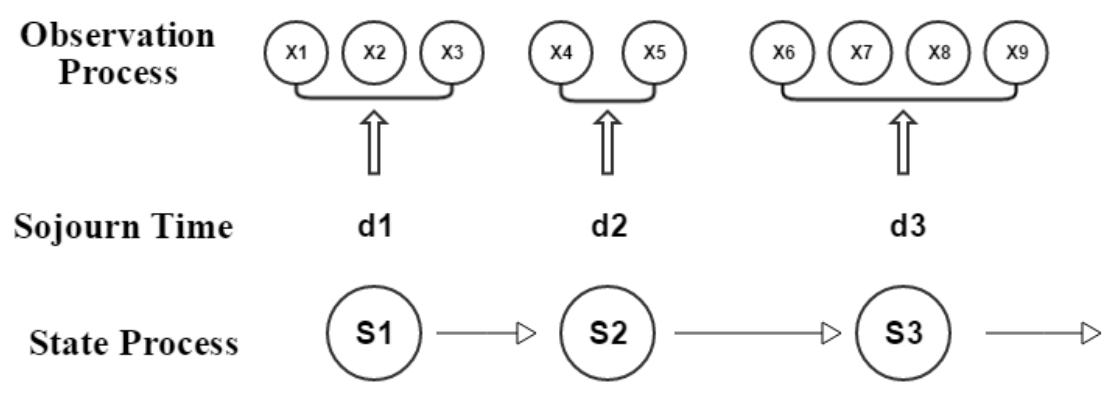

Figure 6: Dynamic Frequency Connectedness of Silver with Gold

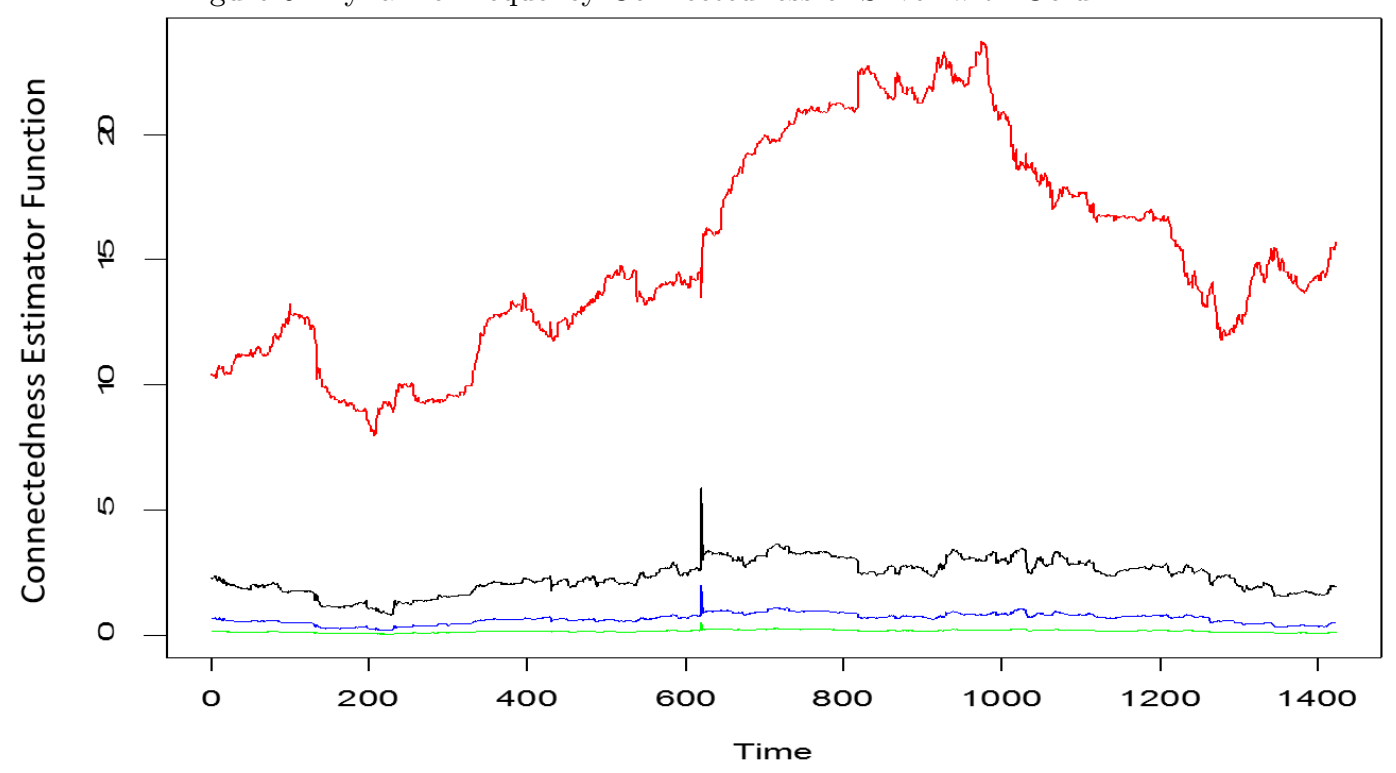


Figure 7: Dynamic Frequency Connectedness of Silver with Oil

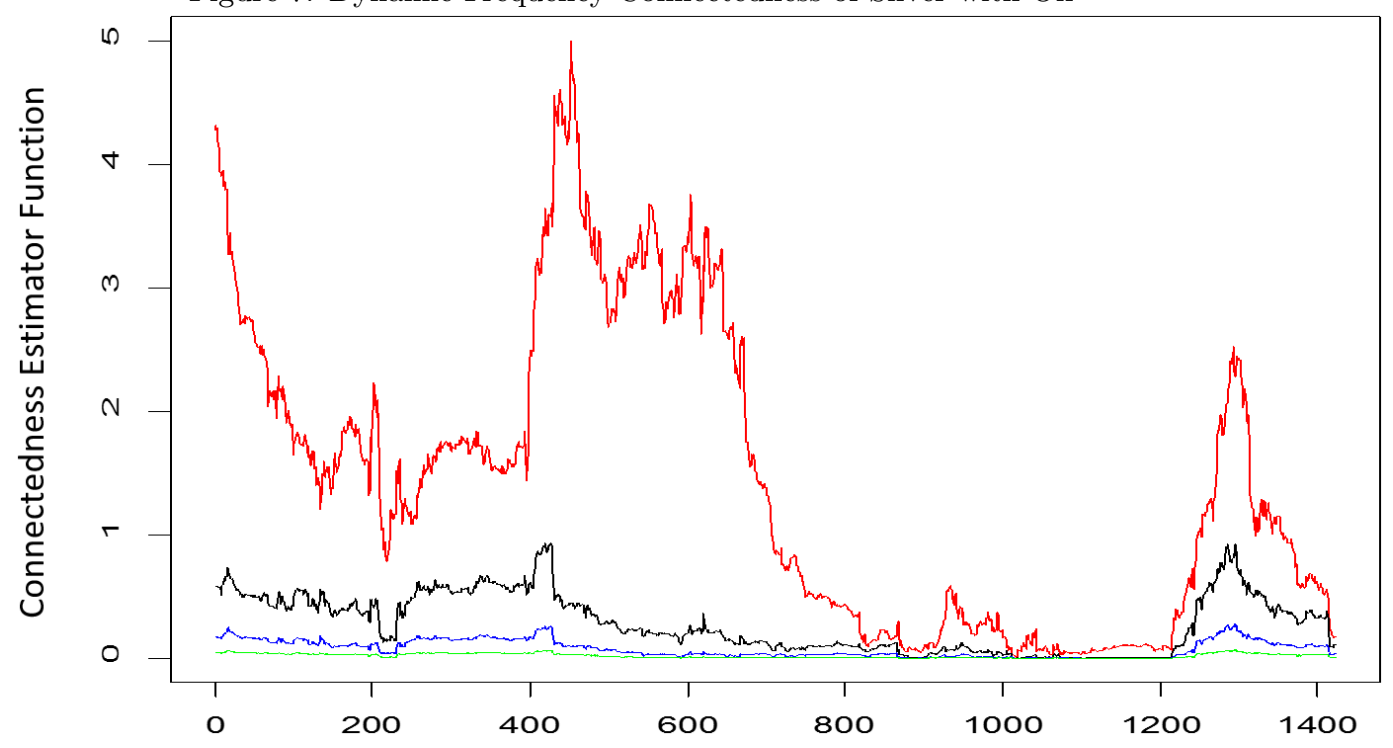

Figure 8: Dynamic Frequency Connectedness of Silver with Equity

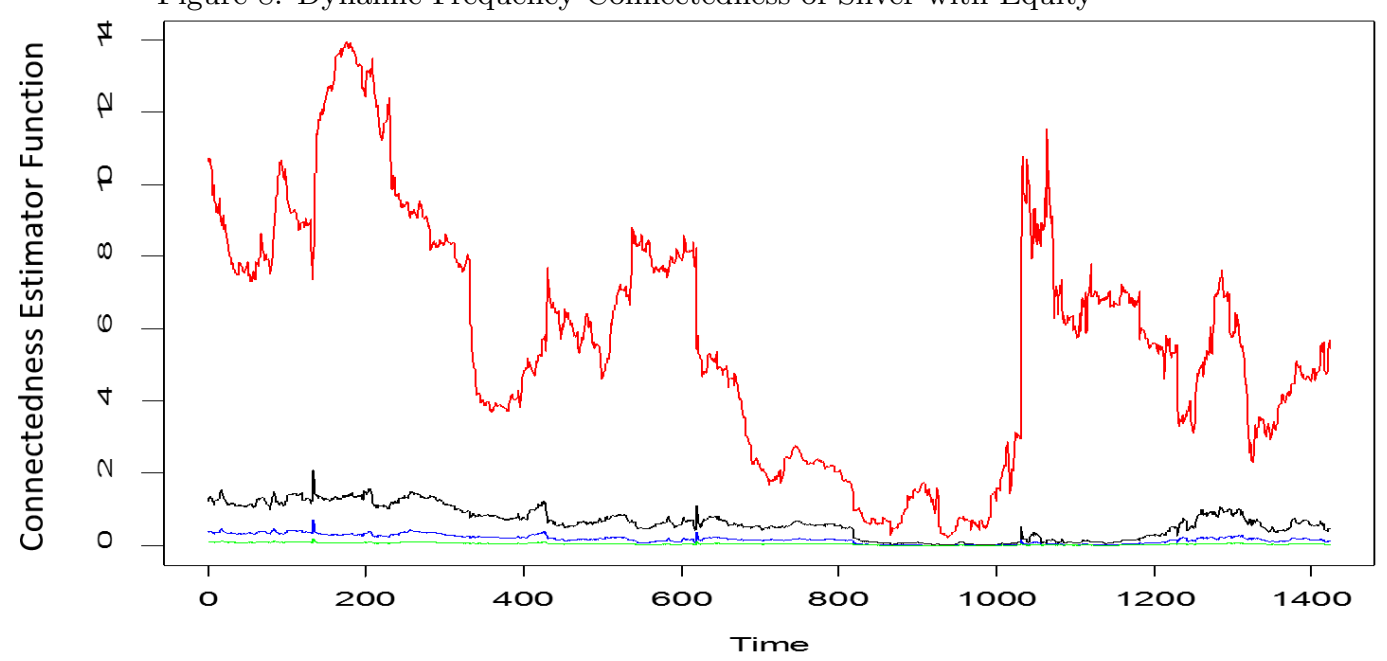


Figure 9: Dynamic Frequency Connectedness of Platinum with Gold

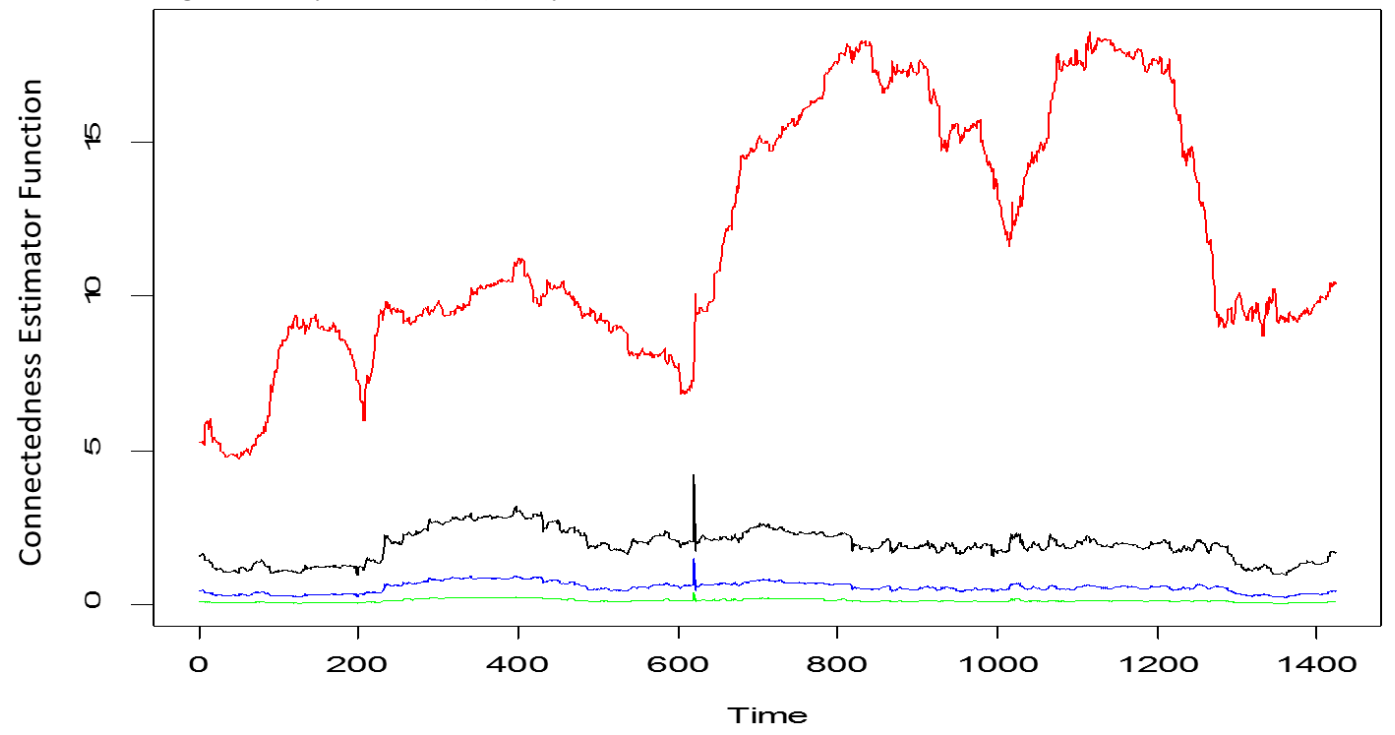

Figure 10: Dynamic Frequency Connectedness of Platinum with Oil

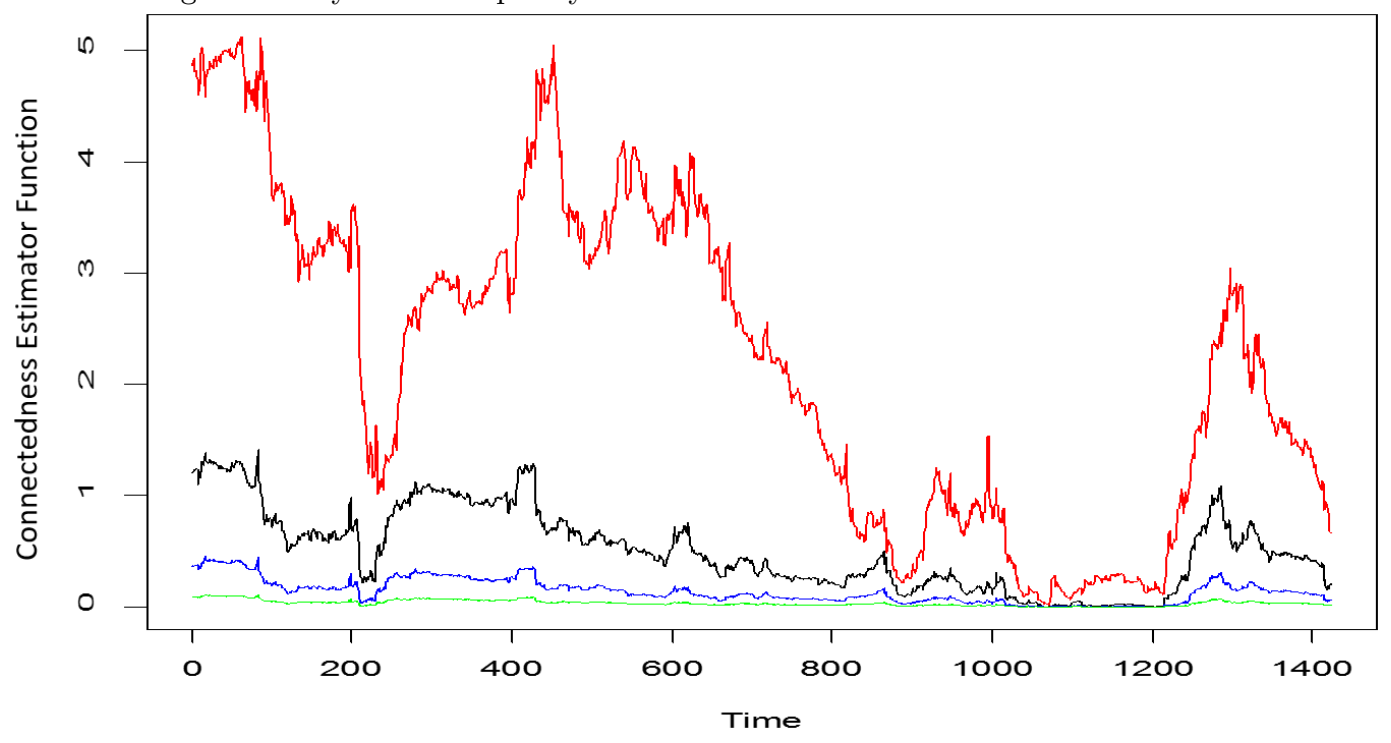


Figure 11: Dynamic Frequency Connectedness of Platinum with Equity

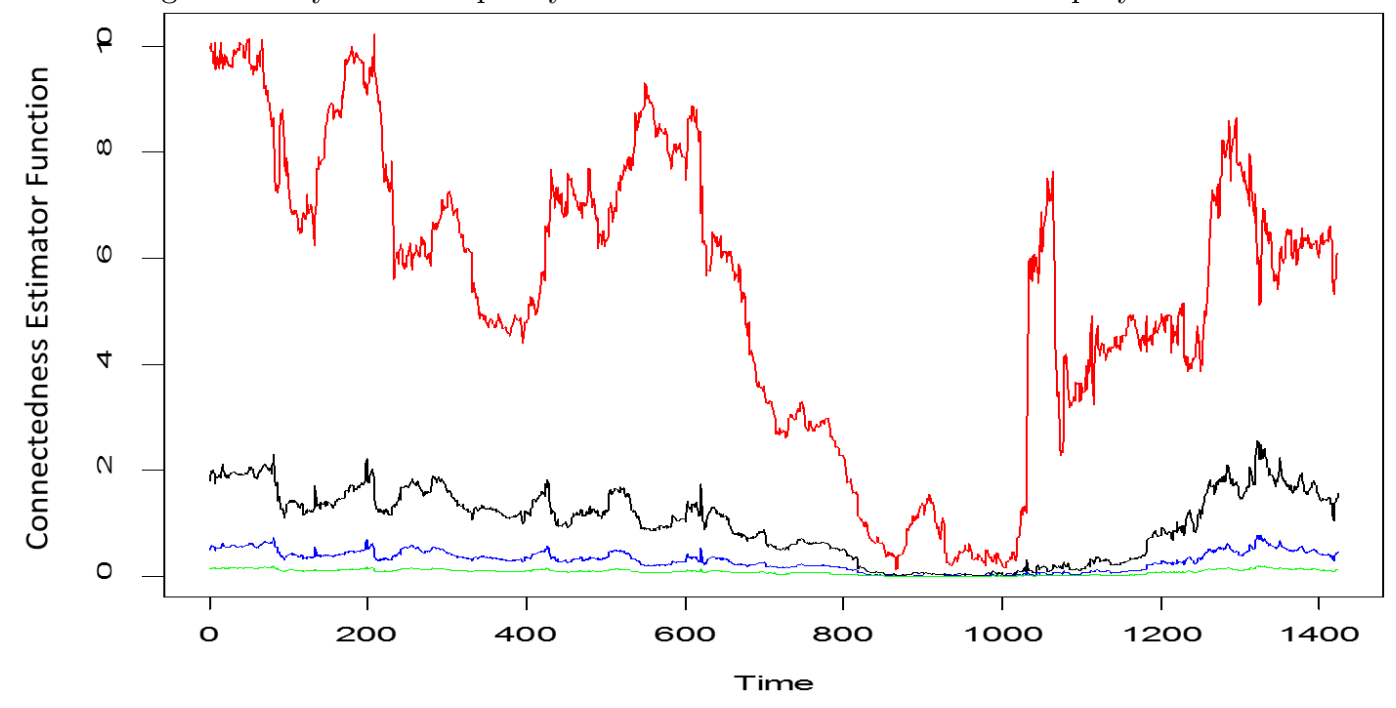

Figure 12: Dynamic Frequency Connectedness of Palladium with Gold

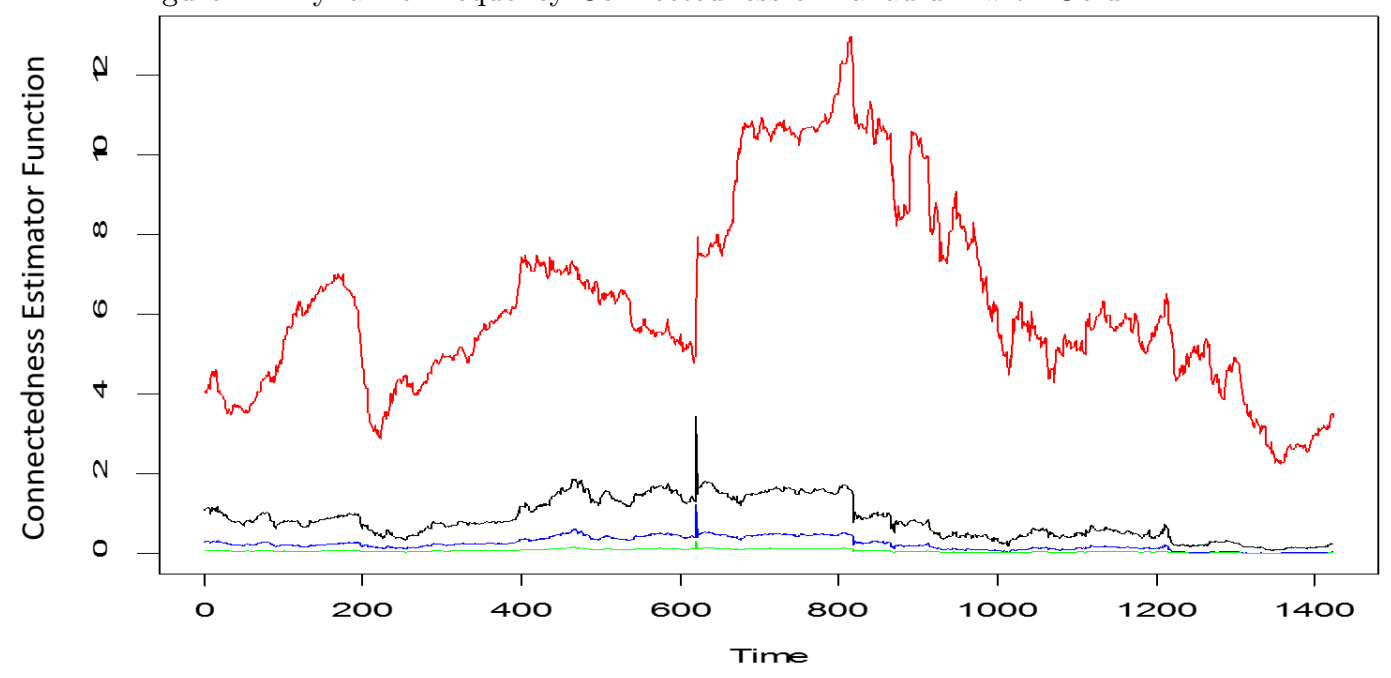


Figure 13: Dynamic Frequency Connectedness of Palladium with Oil

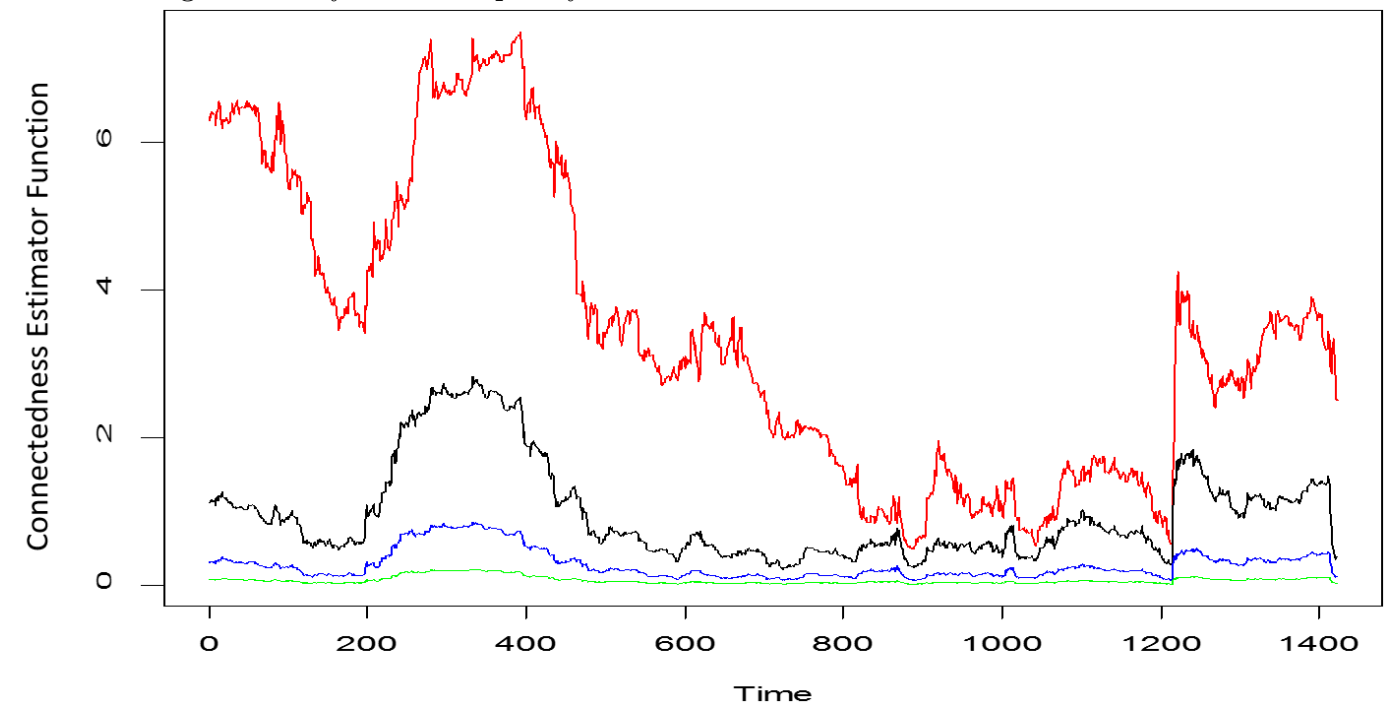

Figure 14: Dynamic Frequency Connectedness of Palladium with Equity

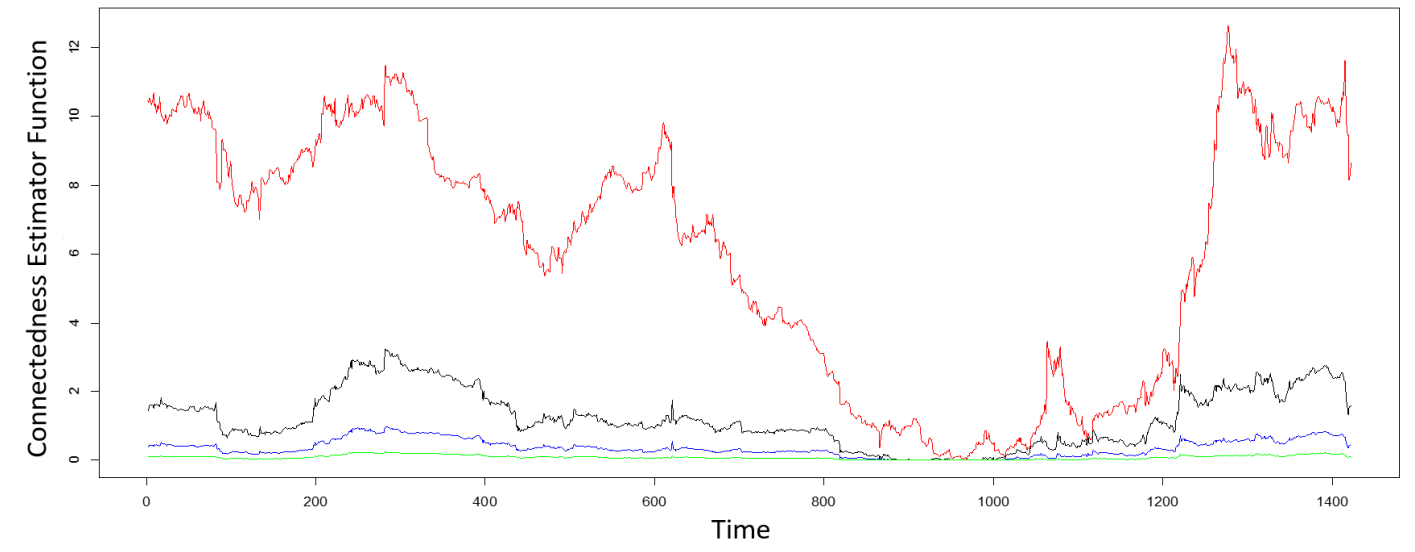


Figure 15: Global Decoding of Fitted two-state HSMM for Silver

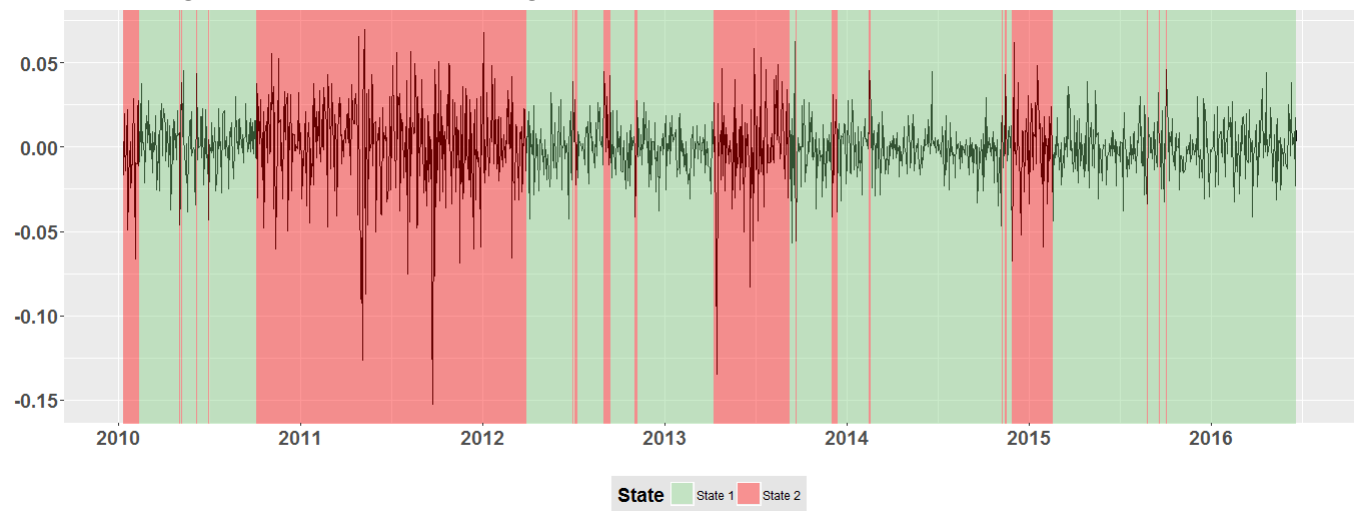

Figure 16: Global Decoding of Fitted two-state HSMM for Platinum

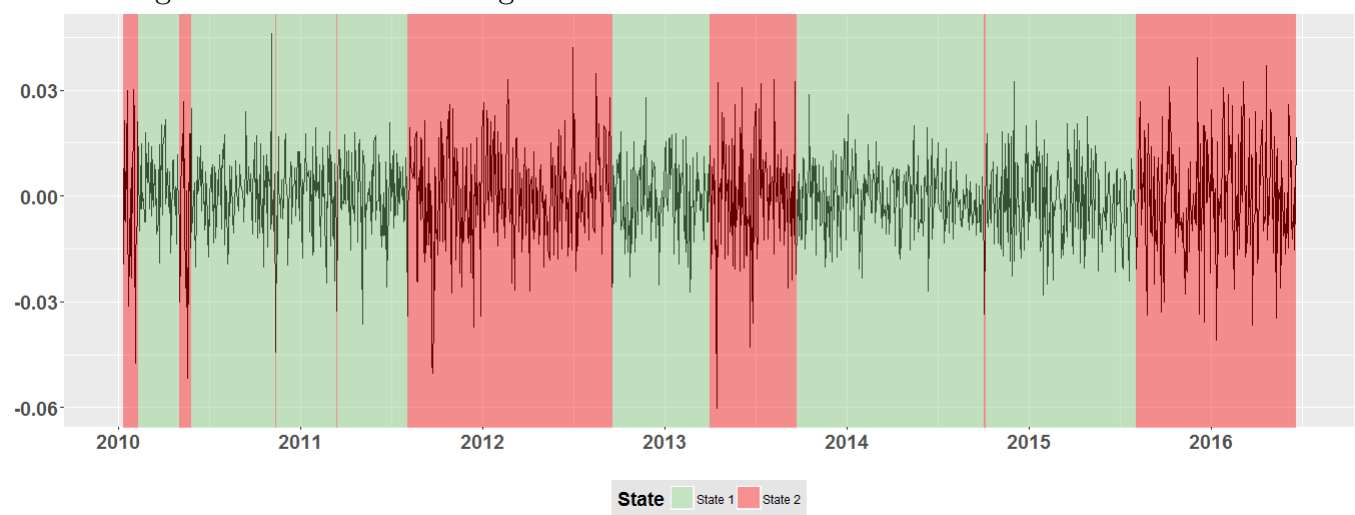

Figure 17: Global Decoding of Fitted two-state HSMM for Palladium

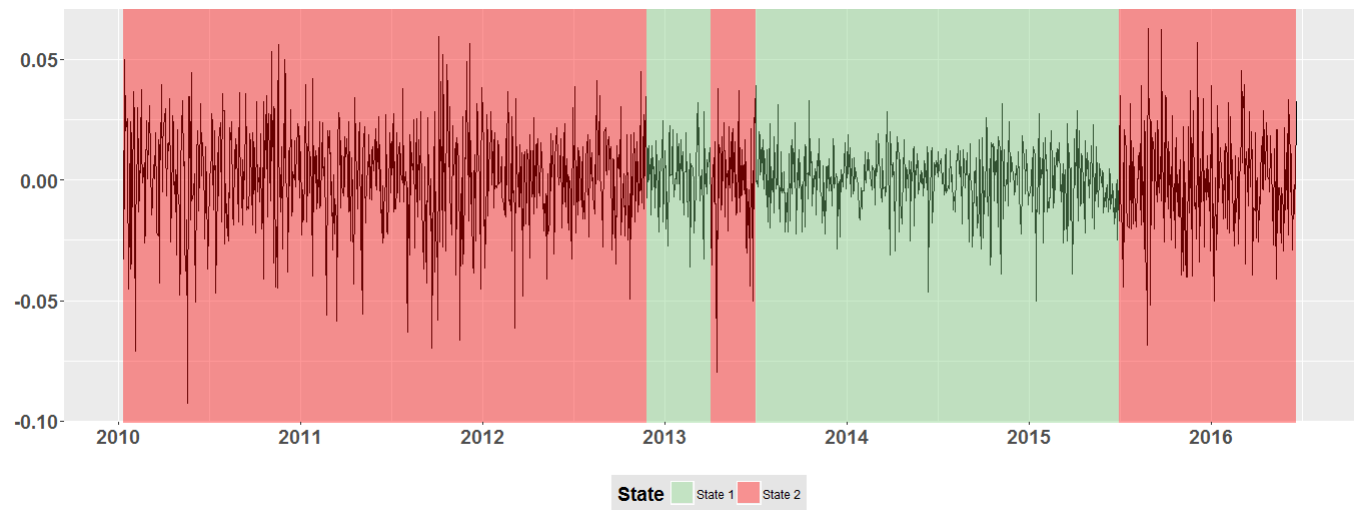


Figure 18: Global Decoding of Fitted three-state HSMM for Silver

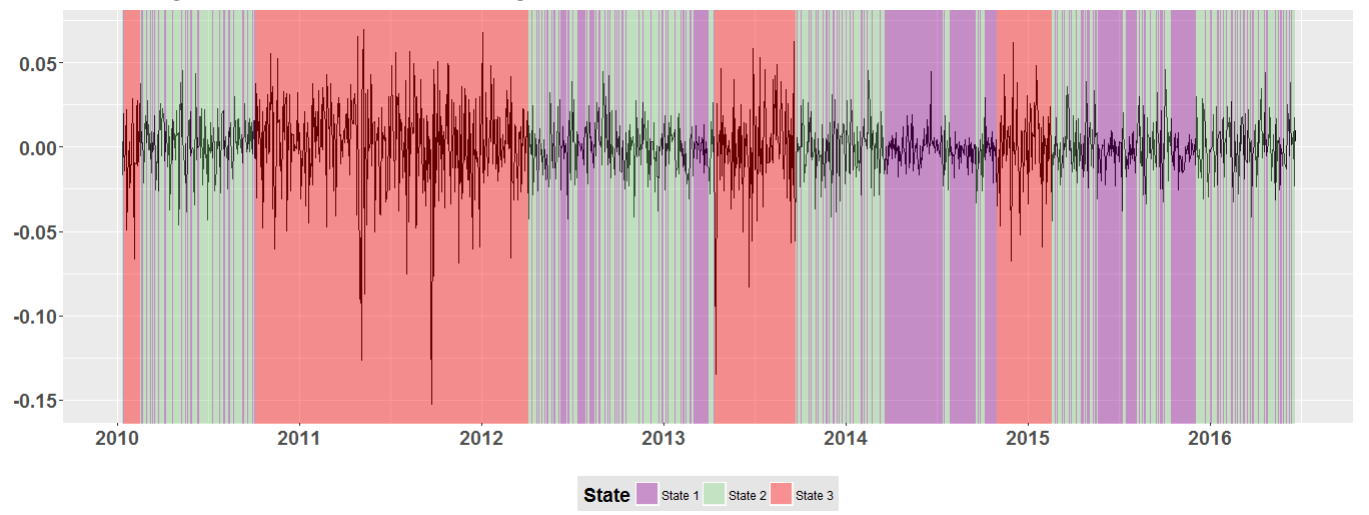

Figure 19: Global Decoding of Fitted three-state HSMM for Platinum

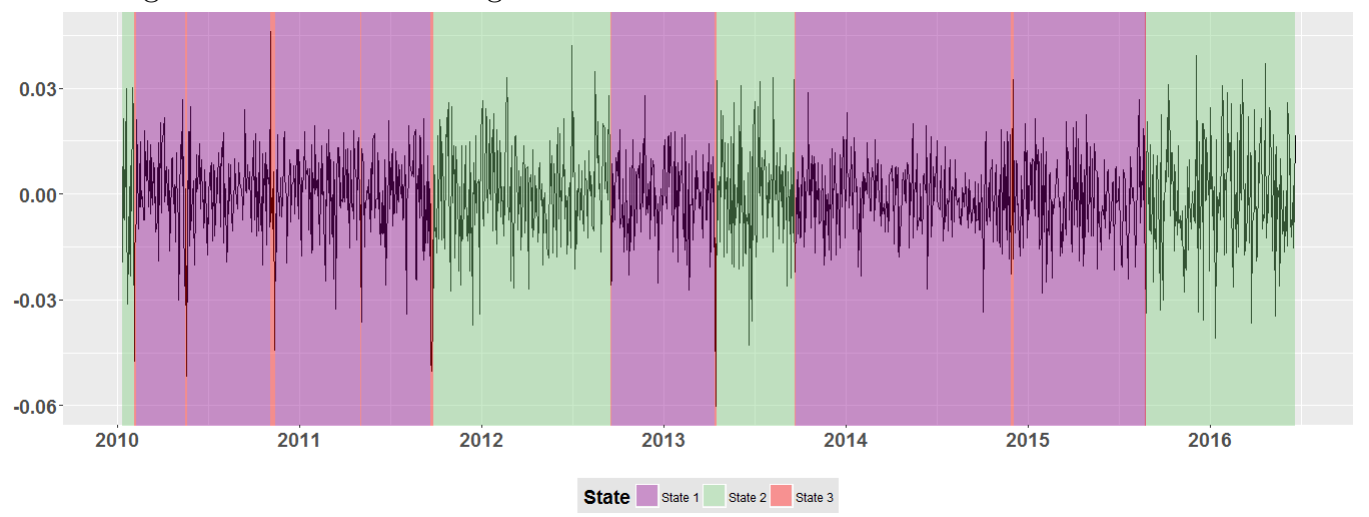

Figure 20: Global Decoding of Fitted three-state HSMM for Palladium

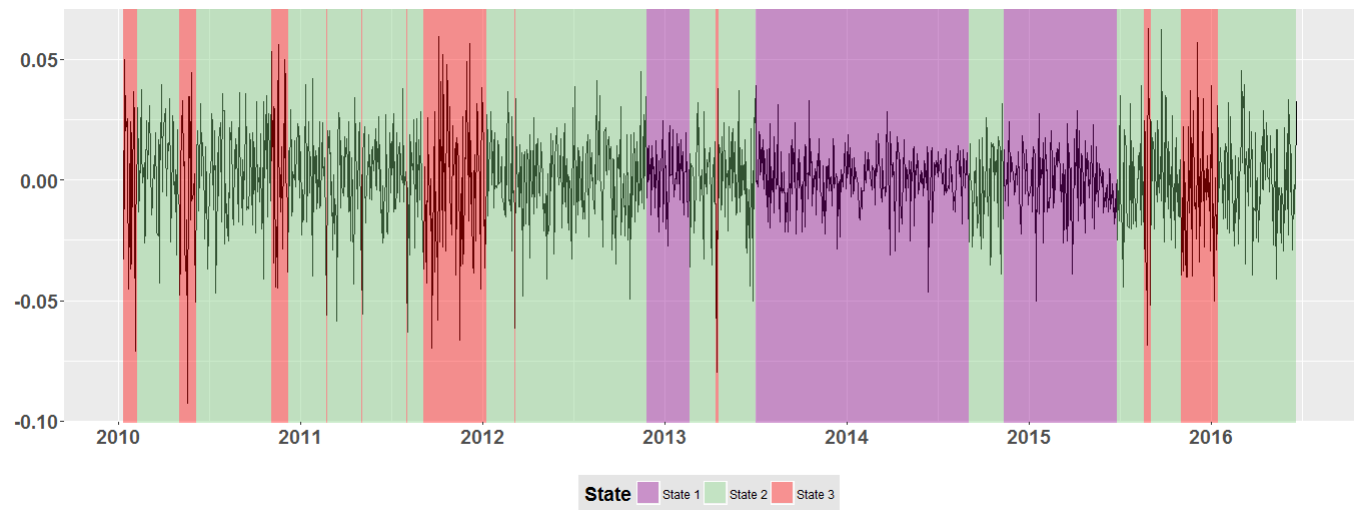


Table 1: Summary statistics of Silver, Platinum, Palladium, Gold, Oil and Equity ETF markets

\begin{tabular}{|c|c|c|c|c|c|c|}
\cline { 2 - 7 } \multicolumn{1}{c|}{} & Silver & Platinum & Palladium & Gold & Oil & Equity \\
\hline Mean & 0.0002 & -0.0003 & 0.0001 & 0.0003 & 0.0002 & -0.0007 \\
\hline Median & 0.0011 & -0.0001 & 0.0008 & 0.0004 & 0.0008 & -0.0003 \\
\hline Maximum & 0.1347 & 0.0462 & 0.063 & 0.107 & 0.1207 & 0.0917 \\
\hline Minimum & -0.1983 & -0.0602 & -0.0926 & -0.0919 & -0.0982 & -0.113 \\
\hline Std. Dev. & 0.0216 & 0.0123 & 0.0185 & 0.0126 & 0.0131 & 0.0221 \\
\hline Skewness & -0.964 & -0.2636 & -0.3961 & -0.2462 & -0.2264 & -0.148 \\
\hline Kurtosis & 10.391 & 4.2321 & 4.4444 & 8.5961 & 12.634 & 5.3491 \\
\hline
\end{tabular}

\begin{tabular}{|c|c|c|c|c|c|c|}
\hline Jarque-Bera & 6121.2 & 121.4 & 183.4 & 3311.1 & 9759.3 & 588.2 \\
\hline Probability & 0.000 & 0.000 & 0.000 & 0.000 & 0.000 & 0.000 \\
\hline
\end{tabular}

Table 2: Stationarity test with structural break

\begin{tabular}{|l|c|c|c|c|}
\hline \multicolumn{2}{|c|}{ Panel A: Univariate unit root test/stationarity test } & \multicolumn{2}{c|}{ Innovation Outlier Test } \\
\hline Variables & P-value (ADF) & P-value (PP) & P-value (Model A) & Break Date \\
\hline Silver & 0.000 & 0.000 & 0.000 & $20 / 07 / 2011$ \\
\hline Platinum & 0.000 & 0.000 & 0.000 & $15 / 01 / 2013$ \\
\hline Palladium & 0.000 & 0.000 & 0.000 & $11 / 03 / 2010$ \\
\hline Gold & 0.000 & 0.000 & 0.000 & $15 / 01 / 2013$ \\
\hline Oil & 0.000 & 0.000 & 0.000 & $10 / 01 / 2011$ \\
\hline Equity & 0.000 & 0.000 & 0.000 & $01 / 06 / 2011$ \\
\hline
\end{tabular}

Regarding the PP test, the selected truncation for the Bartlett Kernel are based on the suggestion by Newey and West (1994). The optimum lag order is selected based on the BIC criterion. The Innovation outlier test follows Perron (1989) assuming that the breaks occur gradually while following the same dynamic path as the innovations. Results for univariate unit root tests with structural breaks are based on the asymptotic one-sided p-values of Vogelsang (1993). 
Table 3: Hatemi-J (2008) Cointegration Test Results

\begin{tabular}{|c|c|c|c|c|c|c|}
\hline Marekts & Zt* test statistic $^{*}$ & $\mathbf{C V} \_\mathbf{1 \%}$ & $\mathbf{C V} \_\mathbf{5 \%}$ & Break one & Break two & Conclusion \\
\hline Palladium-Gold & $-37.459^{* * *}$ & -7.903 & -8.353 & $19 / 01 / 2011$ & $07 / 11 / 2011$ & Cointegrated \\
\hline Palladium-Equity & $-34.562^{* * *}$ & -7.903 & -8.353 & $21 / 01 / 2011$ & - & Cointegrated \\
\hline Palladium-Oil & $-38.002^{* * *}$ & -7.903 & -8.353 & $22 / 04 / 2011$ & - & Cointegrated \\
\hline Platinum-Gold & $-38.276^{* * *}$ & -7.903 & -8.353 & $20 / 02 / 2013$ & $12 / 02 / 2014$ & Cointegrated \\
\hline Platinum-Oil & $-39.464^{* * *}$ & -7.903 & -8.353 & $27 / 03 / 2013$ & $13 / 06 / 2014$ & Cointegrated \\
\hline Platinum-Equity & $-39.193^{* * *}$ & -7.903 & -8.353 & $15 / 04 / 2013$ & $17 / 03 / 2014$ & Cointegrated \\
\hline Silver-Gold & $-41.551^{* * *}$ & -7.903 & -8.353 & $03 / 08 / 2011$ & $20 / 04 / 2012$ & Cointegrated \\
\hline Silver-Oil & $-40.724^{* * *}$ & -7.903 & -8.353 & $27 / 04 / 2011$ & $24 / 04 / 2012$ & Cointegrated \\
\hline Silver-Equity & $-41.041^{* * *}$ & -7.903 & -8.353 & $17 / 08 / 2011$ & $12 / 04 / 2012$ & Cointegrated \\
\hline
\end{tabular}

The Critical values are obtained from Hatemi-J (2008). *** indicates rejection of the null hypothesis of no cointegration at the $1 \%$ levels.

Table 4: Influence on Silver ETF

\begin{tabular}{|c|c|c|c|c|}
\hline & Coefficient & Std. Error & z-Statistic & Prob. \\
\hline \multicolumn{5}{|c|}{ Panel A: Mean Equation } \\
\hline$\delta_{0}$ & -0.0148 & 0.0002 & -0.1123 & 0.9106 \\
\hline$\lambda_{1}$ & 0.0187 & 0.0116 & 1.6219 & 0.1048 \\
\hline$\delta_{1}(\mathrm{GLD})$ & $1.2813^{* * *}$ & 0.0178 & 72.0569 & 0.0000 \\
\hline$\delta_{2}(\mathrm{USO})$ & $0.2685^{* * *}$ & 0.0238 & 11.2723 & 0.0000 \\
\hline$\delta_{3}(\mathrm{VTI})$ & $0.0788^{* * *}$ & 0.0125 & 6.3000 & 0.0000 \\
\hline \multicolumn{5}{|c|}{ Panel B: Variance Equation } \\
\hline$\omega$ & -0.3999 & 0.0932 & -4.2896 & 0.0000 \\
\hline$\alpha_{1}$ & 0.2109 & 0.0287 & 7.3394 & 0.0000 \\
\hline$\gamma_{1}$ & $\underline{0.0053}$ & 0.0185 & 0.2879 & 0.7734 \\
\hline$\beta_{1}$ & 0.9741 & 0.0090 & 107.8562 & 0.0000 \\
\hline GED Parameter & 1.317 & 0.0660 & 19.9617 & 0.0000 \\
\hline Adjusted $R^{2}$ & 0.6854 & & & \\
\hline
\end{tabular}

$* * *, * *$ and $*$ indicate the $1 \%, 5 \%$, and $10 \%$ significance levels, respectively. 
Table 5: Influence on Platinum ETF

\begin{tabular}{|c|c|c|c|c|}
\hline & Coefficient & Std. Error & z-Statistic & Prob. \\
\hline \multicolumn{5}{|c|}{ Panel A: Mean Equation } \\
\hline$\delta_{0}$ & -0.0004 & 0.0002 & -2.2800 & 0.0226 \\
\hline$\lambda_{1}$ & 0.0529 & 0.0152 & 3.4694 & 0.0005 \\
\hline$\delta_{1}(\mathrm{GLD})$ & $0.7300^{* * *}$ & 0.0162 & 45.1628 & 0.0000 \\
\hline$\delta_{2}(\mathrm{USO})$ & $0.2538^{* * *}$ & 0.0205 & 12.3880 & 0.0000 \\
\hline$\delta_{3}(\mathrm{VTI})$ & $0.0723^{* * *}$ & 0.0104 & 6.9353 & 0.0000 \\
\hline \multicolumn{5}{|c|}{ Panel B: Variance Equation } \\
\hline$\omega$ & -0.4396 & 0.1365 & -3.2192 & 0.0013 \\
\hline$\alpha_{1}$ & 0.1232 & 0.0295 & 4.1734 & 0.0000 \\
\hline$\gamma_{1}$ & $\underline{0.0126}$ & 0.0156 & 0.8062 & 0.4201 \\
\hline$\beta_{1}$ & 0.9646 & 0.0127 & 75.7151 & 0.0000 \\
\hline GED Parameter & 1.6885 & 0.0790 & 21.3685 & 0.0000 \\
\hline Adjusted $R^{2}$ & 0.5713 & & & \\
\hline
\end{tabular}

$* * *, * *$ and $*$ indicate the $1 \%, 5 \%$, and $10 \%$ significance levels, respectively.

Table 6: Influence on Palladium ETF

\begin{tabular}{|c|c|c|c|c|}
\hline & Coefficient & Std. Error & z-Statistic & Prob. \\
\hline \multicolumn{5}{|c|}{ Panel A: Mean Equation } \\
\hline$\delta_{0}$ & -0.0001 & 0.0003 & -0.2319 & 0.8166 \\
\hline$\lambda_{1}$ & 0.0705 & 0.0185 & 3.8083 & 0.0001 \\
\hline$\delta_{1}(\mathrm{GLD})$ & $0.6525^{* * *}$ & 0.0306 & 21.3042 & 0.0000 \\
\hline$\delta_{2}(\mathrm{USO})$ & $0.5500^{* * *}$ & 0.0361 & 15.2387 & 0.0000 \\
\hline$\delta_{3}(\mathrm{VTI})$ & $0.1608^{* * *}$ & 0.0197 & 8.1770 & 0.0000 \\
\hline \multicolumn{5}{|c|}{ Panel B: Variance Equation } \\
\hline$\omega$ & -0.2621 & 0.0946 & -2.7719 & 0.0056 \\
\hline$\alpha_{1}$ & 0.0818 & 0.0248 & 3.3039 & 0.0010 \\
\hline$\gamma_{1}$ & $\underline{-0.0301}$ & 0.0149 & -2.0143 & 0.0440 \\
\hline$\beta_{1}$ & 0.9768 & 0.0099 & 98.5405 & 0.0000 \\
\hline GED Parameter & 1.4925 & 0.0681 & 21.9129 & 0.0000 \\
\hline Adjusted $R^{2}$ & 0.4052 & & & \\
\hline
\end{tabular}

$* * *, * *$ and $*$ indicate the $1 \%, 5 \%$, and $10 \%$ significance levels, respectively. 
Table 7: Total Connectedness of White Precious Metal Markets over Different Time Intervals

\begin{tabular}{|c|c|c|c|c|c|c|c|c|c|}
\hline Weekly Cycle & Palladium & Platinum & Silver & Gold & Equity & Oil & From Others* & Net & Conclusion \\
\hline Palladium & 38.413 & 12.738 & 12.356 & 5.071 & 6.74 & 3.72 & 40.625 & 19.817 & net-contributor \\
\hline Platinum & 18.131 & 24.388 & 18.234 & 10.565 & 5.261 & 1.803 & 53.995 & -6.712 & net-recipient \\
\hline Silver & 10.787 & 11.424 & 39.318 & 14.085 & 5.108 & 0.944 & 42.348 & 29.287 & net-contributor \\
\hline Gold & 9.331 & 14.09 & 30.559 & 26.462 & 2.283 & 0.031 & 56.294 & -25.192 & net-recipient \\
\hline Equity & 8.517 & 4.54 & 6.759 & 1.313 & 53.983 & 6.228 & 27.357 & 8.541 & net-contributor \\
\hline Oil & 13.675 & 4.492 & 3.726 & 0.068 & 16.506 & 41.276 & 38.466 & -25.741 & net-recipient \\
\hline Contribution to others** & 60.441 & 47.284 & 71.634 & 31.102 & 35.898 & 12.725 & 259.085 & & \\
\hline Contribution including own $* * *$ & 98.854 & 71.672 & 110.952 & 57.564 & 89.881 & 54.001 & $43.18 \%$ & & \\
\hline \multicolumn{10}{|l|}{ Monthly cycle } \\
\hline Palladium & 7.4544 & 2.342 & 2.2503 & 0.7858 & 1.4282 & 1.1569 & 7.9633 & 3.051 & net-contributor \\
\hline Platinum & 3.6284 & 4.8123 & 3.7193 & 2.0102 & 1.1417 & 0.561 & 11.0606 & -2.7109 & net-recipient \\
\hline Silver & 1.9861 & 1.9665 & 6.3555 & 2.2873 & 0.7004 & 0.2825 & 7.2228 & 5.4673 & net-contributor \\
\hline Gold & 1.5114 & 2.2946 & 4.612 & 4.1082 & 0.2216 & 0.0151 & 8.6546 & -3.2294 & net-recipient \\
\hline Equity & 1.4325 & 0.8375 & 1.2628 & 0.2974 & 8.7946 & 1.0798 & 4.9101 & 2.2957 & net-contributor \\
\hline Oil & 2.4558 & 0.9092 & 0.8456 & 0.0444 & 3.714 & 6.8862 & 7.969 & -4.8737 & net-recipient \\
\hline Contribution to others** & 11.0143 & 8.3498 & 12.6901 & 5.4252 & 7.2058 & 3.0953 & 47.7804 & & \\
\hline Contribution including own*** & 18.4687 & 13.1621 & 19.0456 & 9.5334 & 16.0004 & 9.9815 & $7.96 \%$ & & \\
\hline \multicolumn{10}{|l|}{ Quarterly cycle } \\
\hline Palladium & 2.129 & 0.668 & 0.643 & 0.223 & 0.423 & 0.349 & 2.306 & 0.809 & net-contributor \\
\hline Platinum & 1.027 & 1.395 & 1.085 & 0.59 & 0.332 & 0.166 & 3.199 & -0.823 & net-recipient \\
\hline Silver & 0.555 & 0.551 & 1.783 & 0.646 & 0.191 & 0.082 & 2.024 & 1.624 & net-contributor \\
\hline Gold & 0.423 & 0.646 & 1.292 & 1.163 & 0.058 & 0.004 & 2.423 & -0.857 & net-recipient \\
\hline Equity & 0.412 & 0.244 & 0.375 & 0.092 & 2.521 & 0.318 & 1.443 & 0.672 & net-contributor \\
\hline Oil & 0.699 & 0.266 & 0.252 & 0.015 & 1.113 & 1.976 & 2.345 & -1.425 & net-recipient \\
\hline Contribution to others** & 3.116 & 2.376 & 3.647 & 1.566 & 2.115 & 0.92 & 13.74 & & \\
\hline Contribution including own $* * *$ & 5.245 & 3.771 & 5.43 & 2.729 & 4.636 & 2.896 & $2.29 \%$ & & \\
\hline \multicolumn{10}{|l|}{ Yearly cycle } \\
\hline Palladium & 0.532 & 0.167 & 0.161 & 0.056 & 0.106 & 0.088 & 0.577 & 0.201 & net-contributor \\
\hline Platinum & 0.256 & 0.349 & 0.272 & 0.148 & 0.083 & 0.042 & 0.8 & -0.207 & net-recipient \\
\hline Silver & 0.138 & 0.137 & 0.445 & 0.161 & 0.047 & 0.021 & 0.505 & 0.407 & net-contributor \\
\hline Gold & 0.106 & 0.161 & 0.322 & 0.291 & 0.014 & 0.001 & 0.605 & -0.213 & net-recipient \\
\hline Equity & 0.103 & 0.061 & 0.094 & 0.023 & 0.63 & 0.08 & 0.361 & 0.168 & net-contributor \\
\hline Oil & 0.175 & 0.067 & 0.063 & 0.004 & 0.279 & 0.494 & 0.587 & -0.357 & net-recipient \\
\hline Contribution to others** & 0.778 & 0.594 & 0.912 & 0.392 & 0.53 & 0.231 & 3.437 & & \\
\hline
\end{tabular}

* From others: Measures spillovers from all markets $\mathrm{j}$ to market $\mathrm{i} ;{ }^{* *}$ Contribution to others: Measures spillovers from market $\mathrm{i}$ to all markets $\mathrm{j}$; ${ }^{* * *}$ Contribution including own: Measures spillovers from market $\mathrm{i}$ to all markets $\mathrm{j}$, including contribution from own innovations to market $\mathrm{i}$. The other columns contain net pairwise $(\mathrm{i}, \mathrm{j})$-th spillovers indices 
Table 8: Estimation Results of Two-state HSMM

\begin{tabular}{llcccccc}
\hline & & \multicolumn{2}{c}{ Palladium } & \multicolumn{2}{c}{ Platinum } & \multicolumn{2}{c}{ Silver } \\
& & State 1 & State 2 & State 1 & State 2 & State 1 & State 2 \\
\hline \multirow{2}{*}{$\begin{array}{c}\text { Conditional } \\
\text { Distribution }\end{array}$} & Mean*10000 & 11.406 & -8.48 & -0.931 & -6.714 & 1.217 & -3.947 \\
& Variance*10000 & 1.356 & 5.364 & 0.845 & 2.562 & 1.329 & 8.839 \\
& z-statistic & 2.375 & -1.177 & -0.312 & -1.089 & 0.336 & -0.327 \\
\hline \multirow{2}{*}{ Sojourn } & $\mathrm{r}$ & 0.051 & 0.098 & 0.686 & 0.058 & 0.146 & 0.019 \\
Time & $\mathrm{p}$ & 0.013 & 0.023 & 0.061 & 0.008 & 0.04 & 0.014 \\
& No. of Days & 588 & 1034 & 948 & 674 & 1015 & 607 \\
& Average Sojourn Time & 117.6 & 206.8 & 94.8 & 61.263 & 17.203 & 10.466 \\
\hline
\end{tabular}

Table 9: Estimation Results of Three-state HSMM

\begin{tabular}{|c|c|c|c|c|c|c|c|c|c|c|}
\hline & & \multicolumn{3}{|c|}{ Palladium } & \multicolumn{3}{|c|}{ Platinum } & \multicolumn{3}{|c|}{ Sliver } \\
\hline & & State 1 & State 2 & State 3 & State 1 & State 2 & State 3 & State 1 & State 2 & State 3 \\
\hline \multirow{3}{*}{$\begin{array}{l}\text { Conditional } \\
\text { Distribution }\end{array}$} & Mean*10000 & 6.224 & 12.142 & -39.573 & -0.844 & 5.546 & -69.091 & -6.255 & 12.298 & -24.461 \\
\hline & Variance*10000 & 1.165 & 2.832 & 8.301 & 0.939 & 2.096 & 4.593 & 0.397 & 3.31 & 10.87 \\
\hline & z-statistic & 1.298 & 2.155 & -2.051 & -0.278 & 0.923 & -1.644 & -2.193 & 1.581 & -1.798 \\
\hline \multirow{3}{*}{ TPM } & State 1 & $0.00 \%$ & $99.96 \%$ & $0.04 \%$ & $0.00 \%$ & $0.09 \%$ & $99.91 \%$ & $0.00 \%$ & $93.86 \%$ & $6.14 \%$ \\
\hline & State 2 & $23.25 \%$ & $0.00 \%$ & $76.75 \%$ & $0.42 \%$ & $0.00 \%$ & $99.58 \%$ & $93.07 \%$ & $0.00 \%$ & $6.93 \%$ \\
\hline & State 3 & $0.04 \%$ & $99.96 \%$ & $0.00 \%$ & $36.76 \%$ & $63.24 \%$ & $0.00 \%$ & $0.00 \%$ & $100.00 \%$ & $0.00 \%$ \\
\hline \multirow{4}{*}{$\begin{array}{c}\text { Sojourn } \\
\text { Time }\end{array}$} & $\mathrm{r}$ & 0.375 & 2.148 & 0.428 & 2.874 & 0.12 & 6.741 & 0.044 & 9.524 & 0.072 \\
\hline & $\mathrm{p}$ & 0.008 & 0.091 & 0.049 & 0.043 & 0.007 & 0.848 & 0.072 & 0.878 & 0.012 \\
\hline & No. of Days & 507 & 892 & 223 & 1016 & 580 & 26 & 488 & 547 & 587 \\
\hline & Average Sojourn Time & 169 & 63.714 & 20.273 & 145.143 & 116 & 2.364 & 2.085 & 2.348 & 146.75 \\
\hline
\end{tabular}

